IZA DP No. 7366

Language Proficiency of Migrants:

The Relation with Job Satisfaction and Matching

Hans G. Bloemen

April 2013 


\title{
Language Proficiency of Migrants: The Relation with Job Satisfaction and Matching
}

\author{
Hans G. Bloemen \\ VU University Amsterdam \\ and IZA
}

\section{Discussion Paper No. 7366 \\ April 2013}

\author{
IZA
}

P.O. Box 7240

53072 Bonn

Germany

\author{
Phone: +49-228-3894-0 \\ Fax: +49-228-3894-180 \\ E-mail: iza@iza.org
}

\begin{abstract}
Any opinions expressed here are those of the author(s) and not those of IZA. Research published in this series may include views on policy, but the institute itself takes no institutional policy positions. The IZA research network is committed to the IZA Guiding Principles of Research Integrity.
\end{abstract}

The Institute for the Study of Labor (IZA) in Bonn is a local and virtual international research center and a place of communication between science, politics and business. IZA is an independent nonprofit organization supported by Deutsche Post Foundation. The center is associated with the University of Bonn and offers a stimulating research environment through its international network, workshops and conferences, data service, project support, research visits and doctoral program. IZA engages in (i) original and internationally competitive research in all fields of labor economics, (ii) development of policy concepts, and (iii) dissemination of research results and concepts to the interested public.

IZA Discussion Papers often represent preliminary work and are circulated to encourage discussion. Citation of such a paper should account for its provisional character. A revised version may be available directly from the author. 


\section{ABSTRACT \\ Language Proficiency of Migrants: The Relation with Job Satisfaction and Matching*}

We empirically analyze the language proficiency of migrants in the Netherlands. Traditionally, the emphasis in studying language proficiency and economic outcomes has been on the relation between earnings and indicators for language proficiency, motivated by the human capital theory. Here we analyze whether there is a relation between proficiency of the destination language and job level. A lack of language skills may induce the migrant to work in jobs of a lower level leading to lower job satisfaction. We use subjective survey information about job satisfaction and the fit between the migrant's education and skill level and the job. We also use objective information on professional level. For men, we find evidence for a positive relationship between indicators for language proficiency and satisfaction with work type and professional level.

JEL Classification: J15, J24, J28

Keywords: immigrants, skills, job satisfaction

Corresponding author:

Hans G. Bloemen

Department of Economics

VU University Amsterdam

De Boelelaan 1105

1081 HV Amsterdam

Netherlands

E-mail: h.g.bloemen@vu.nl

\footnotetext{
* This paper draws on data of the LISS panel of CentERdata. This paper benefited from comments by Federica Teppa, and (seminar and conference) participants at UAB Barcelona, the MESS Workshop, ESEM, Université Paris I, Oded Galor and other participants at the IZA Migration Meeting, University of Basque Country in Bilbao, Alexander Humboldt Seminar Mannheim.
} 


\section{Introduction}

Are migrants selected into lower level and less satisfactory jobs due to a lack of proficiency in the destination country's language? The aim of this study is to analyze this question using data from the Longitudinal Internet Studies for the Social Sciences (LISS) for the Netherlands as a destination country. The literature, of which Chiswick (2007) provides an overview, shows that the language proficiency of migrants has a potential impact on labour market outcomes. Most often analyzed is the relation between language proficiency and earnings, recognizing that language skills are part of the individual's human capital. The literature also addresses the determinants of the migrant's language proficiency. There are studies for different destination countries, with different destination languages. Chiswick and Miller (1994, 2001) provide evidence for Canada, with English as the main language of destination, while Chiswick (1998) studies the case of Israel, and Dustmann (1994) and Dustmann and Van Soest (2001) analyze Germany. Dustmann and Fabbri (2003) not only analyze earnings as an outcome variable but also employment. Gonzalelez (2010) does an analysis for Spain and finds effects of host language skills on employment but not on earnings.

The destination language of our analysis is Dutch. As pointed out by Chiswick (2007) it is interesting to analyze destination languages that are less common than the English language. Moreover, the Netherlands has a rich variation in the migrant population. ${ }^{1}$ To address the question whether migrants with lower proficiency levels are selected into lower level jobs, we use both subjective and objective outcome measures. The LISS survey contains a direct question to respondents to indicate whether education or skills suit the work that they perform. We analyze whether the response to that question is influenced by language proficiency. In addition, we analyze whether satisfaction with various aspects of the job depends on proficiency. Job satisfaction is also considered as an outcome variable in the education mismatch literature, albeit in different ways. Chevalier (2003) uses information about job satisfaction, together with other job features, to construct a measure of mismatch. Mavromaras et al. (2010) use job satisfaction directly as an outcome variable, like we do in

\footnotetext{
${ }^{1}$ Migrants in the Netherlands originate from (former) colonies of the Netherlands, like Suriname, who know the Dutch language relatively well, but who often speak their own language among each other, from western countries, with languages that are related to Dutch (like German), and from non-western countries (like Morocco or Asian countries), whose languages are hardly related to the Dutch language.
} 
our analysis. Their motivation for using job satisfaction an an outcome is that it not only provides information about restrictions faced by the worker, but it also incorporates the worker's preferences: a low job level relative to the education level may have been the result of choice, rather than restriction. ${ }^{2}$ Applying it to the context of migration, a relatively low job level need not lead to dissatisfaction if working conditions are favourable to the migrant. But if someone involuntarily ends up in a lower-level job due to low destination country language skills, this may result into a lower satisfaction with various aspects of the job. As an objective outcome, we look at the professional level. If the underlying mechanism runs from language proficiency via professional level (objective outcome) to job suitability and satisfaction (subjective outcomes), then directly measuring the impact of language proficiency on subjective outcomes skips the intermediate step. Therefore, in an additional analysis using the objective information, we first establish the relationship between professional level and the subjective outcomes, and next the relationship between language proficiency and the professional level. To narrow down the scope, we focus on the impact of language proficiency level on the probability of ending up in an unskilled manual job.

In measuring the impact of language proficiency on labour market outcomes some econometric issues deserve attention. Our indicator for language proficiency comes from survey information and we need to account for the fact that this is an indicator of an underlying latent language proficiency level. Moreover, if migrants are aware of a possible desirable impact of language proficiency on labour market outcomes, they may invest in language skills in order to improve upon labour market outcomes. This actually may be part of the impact of interest, but what is more important is that there may be unobserved individual specific effects that correlate both with language proficiency and with labour market outcomes. Since we have panel data at our disposal we can specify a two equations random effects model for language proficiency and the labour market outcome of interest and identify correlation in random effects between the two using the panel nature of the data, and this identification does not lean on instrumentation. Nevertheless we still need to instrument language proficiency to address the idiosyncratic correlation between the two equations that we wish to allow for. Instrumentation and the potential endogeneity issue of language proficiency was

\footnotetext{
${ }^{2}$ For instance if lower level jobs allow for more flexibility or less stress.
} 
addressed by Chiswick and Miller (1995) and Dustmann and Van Soest (2001). The former use theoretical exclusions restrictions (family variables affect proficiency but not earnings), while the latter use parental education to instrument proficiency. We follow a different approach by using a measure of linguistic distance, described by Bakker et al. (2009) in the linguistic literature and applied by Isphording and Otten (2011) in a study of determinants of language proficiency of migrants in Germany. We have survey information about the language that someone grew up speaking and we use the linguistic distance for that language as an instrument. To check whether the measure of linguistic distance correlates with other distance measures, which may violate the exclusion restriction, we include geographical distance and genetic distance (from Spolaore and Wacziarg, 2009, see also Ashraf and Galor, 2012) in our analysis. In addition to linguistic distance, we considered survey information about respondents' personality and values as instruments which add to the explanation of language proficiency. However, a priori these are less likely to satisfy the exclusion restriction, but we use them for analysis of robustness of our results.

Thus, our analysis consists of several steps. First, we analyze the determinants of language proficiency. This step is meant to identify the relevant background characteristics and to shed light on the quality of our language proficiency indicator. Next, we apply the simultaneous two equations model to the subjective labour market outcomes on job suitability and job satisfaction, after which we analyze the professional level. The data come from the LISS panel. We use four waves from the years 2008 through 2011. This survey contains relevant information for our analysis. We can identify the country of birth of a respondent, we have information on the number of years the migrant is residing in the Netherlands, and the language(s) the migrant grew up with, and it contains information about the proficiency of speaking (fluency) and reading (literacy).

Results show that the analysis of determinants of language proficiency identifies variables that are in line with determinants discussed in the literature (Chiswick, 2007), which gives confidence in our observed measure of language proficiency. In our analysis of labour market outcomes we find for men a positive relationship between language proficiency and satisfaction with the type of work, and we find that for men language proficiency adds to the match between education/skills and the job. Moreover, men are less likely to end up in 
a low-skilled manual job if they have a higher proficiency. For women, we do not find any robust effects. There is some evidence for women that a low level of proficiency leads to problems in performing their jobs, but the result is not robust. However, an additional analysis using employment as an outcome variable shows that for women language proficiency may influence selection into employment, whereas for men such a selection effect is absent.

In section 2 we describe the data from the LISS survey. In section 3 we describe the measure for linguistic distance. In section 4 we analyze the determinants of language proficiency. Section 5 presents the results of analyzing the relationship between language proficiency and labour market outcomes.

\section{Data}

Data come from the LISS $^{3}$ panel, a panel survey drawn from the population in the Netherlands, consisting of roughly 5000 households (8000 individuals). ${ }^{4}$ We use four waves for the years 2008 through 2011. ${ }^{5}$ The LISS survey collects information on a great deal of topics, including the household's economic situation (income, assets), work and schooling, religion and ethnicity, and health. Individuals reporting to be born outside the Netherlands are defined as migrants. We exclude individuals born in Belgium as one of the major languages in Belgium is Flemish, similar to Dutch. All Belgian immigrants in the survey have the highest proficiency level according to our survey indicators. In our base sample, we select individuals older than 22 and younger than 65 for which the relevant information is observed. ${ }^{6}$ This results in a sample of 1303 individuals-years observations (pooled over the four waves) of

\footnotetext{
${ }^{3}$ Longitudinal Internet Studies for the Social Sciences.

${ }^{4}$ A detailed description of the sample selection procedure can be found in Scherpenzeel (2009).

${ }^{5}$ The panel started in October 2007 and 2008 was the first complete year of data collection. In 2011, LISS introduced the 'Immigrant Panel'. This is a new panel consisting of "around 2400 individuals, of which 1700 are of non-Dutch origin" (source: LISS. The remaining 700 of Dutch origin serve as a control group). This is not the panel we are using for our current study. Our study uses the regular panel, initiated in 2007, which also contains immigrants. In 2011, these immigrants are still in the regular panel (the 'Immigrant Panel' was newly drawn), but no refreshment was added. The 'Immigrant Panel' provides less details about country or language of origin (the emphasis is on the bigger groups of migrants in terms of country of origin) and also does not contain the same question on language proficiency.

${ }^{6}$ After the age of 22 , most individuals will have finished their education and are available for the labour market. At the age of 65 people are usually eligible for the state pension. Many Dutch workers will be eligible for some kind of early retirement arrangement, but migrants who move in at a later age than 15 will not have full coverage for the first pillar pension.
} 
549 different individuals. We use this as our base sample for analyzing the determinants of language proficiency. For the second part of our analysis (the labour market outcomes) we use smaller subsamples, depending on the availability of the information on the outcome variables, which are typically observed for individuals with a job.

As all sample participants, the migrants participating in the survey are drawn from the municipal registers. ${ }^{7}$ The consequence for the selection of migrants is limited since migrants not included in these registers are staying on a so called "short stay visa" 8 which is for a period of at most 3 months, issued to people who are visiting friends or relatives, or are in the Netherlands as a tourist. Everybody else who comes to the Netherlands for more than 3 months, also if work or study is the main reason for migration, needs to be registered at the GBA to receive a residence permit, whether temporary or permanent. ${ }^{9}$ Scherpenzeel (2009) reports that the sample is biased toward households in which at least one adult is capable of understanding the Dutch language ${ }^{10}$ and provides some rough numbers indicating the consequence of this selection: she shows that $3 \%$ of the gross sample (i.e. the addresses initially drawn from GBA) is classified as 'non usable' which includes addresses that are dropped due to language problems, in addition to "among other things, non-existing or noninhabited addresses, companies, long term infirm or disabled respondents." This relatively small percentage shows that the impact on selection into the panel was limited, although once selected in the panel there can be additional implications for, say, item non-response. ${ }^{11}$ The analysis of language proficiency in section 3 will shed more light on the quality of the $\operatorname{data.~}^{12}$

Information about fluency and literacy is obtained with two survey questions. The first, for fluency, is:

\footnotetext{
${ }^{7}$ Households in the LISS are drawn from the GBA, "Gemeentelijke basisadministratie".

8 Visum Kort Verblijf.

${ }^{9}$ Drawing from the municipal registers automatically excludes illegal, non-registered, immigrants.

10 The questionnaire is computer based and questions appear in Dutch to respondents. However, questionnaires in English are downloadable from the LISS site. It is not known to what extent respondents make use of this opportunity.

11 Selection bias would be a more serious problem if we were studying the impact of language proficiency on social exclusion. Here we mainly focus on employed workers who at least must have some contacts in the Dutch society.

12 No impact of relevant background variables on language proficiency would be found if sample selection were to remove a large share of the sample. However, the analysis in the next section shows that various explanatory variables show a significant impact in the expected direction.
} 
"When having conversations in Dutch, do you ever have trouble speaking the Dutch language?"13

1. yes, often have trouble/do not speak Dutch ${ }^{14}$

2. yes, sometimes

3. no, never

A similar question is asked for reading:

"When reading newspapers, letters or brochures, do you ever have trouble understanding the Dutch language?"

1. yes, often have trouble/do not speak Dutch

2. yes, sometimes

3. no, never

For our base sample, we selected individuals that show no nonresponse to these two questions, and for which basic characteristics (education level, gender, and the number of years they live in the Netherlands) are observed. ${ }^{15}$

Table 1 contains descriptive statistics for our sample. The first column shows the sample selected on age $(22<$ age $<65)$. The second column shows observations that are more attached to the labour market (we dropped students, retired, disabled, and housewives). The first line shows information about the country or area of birth. The biggest groups of migrants in the Netherlands originate from Turkey, Morocco, the Dutch Antilles, Suriname,

\footnotetext{
13 The phrasing of the question differs from other surveys known from the literature, where respondents are often asked to report their speaking skills on a scale of 1 to 5 , ranging from very bad to very good. This way of phrasing the question requires the respondent to be aware of what is 'good' or 'bad' as far as speaking the language is concerned. Dustmann and Van Soest (2001) discuss the issue of measurement error and the phenomenon that migrants may adjust downward their judgment of their own fluency the longer they are in the country. The phrasing of the question in the LISS is implicitly linked to the event of 'having trouble speaking' the language. On the one hand, this gives the respondent a reference point to judge what is good or bad, but on the other hand the outcome of the response may be related to the respondent's situation. Someone in employment, or doing effort to find a job, may respond differently than someone who stays at home and does the housework.

14 A priori, the response in this category may be low for a sample drawn from the municipal registers.

15 Only very few observations are lost by these latter selections.
} 
and Indonesia, the latter three being (former) Dutch colonies. ${ }^{16}$ Individuals from other origins are classified into groups. Originally, our idea was to classify respondents into groups of languages that are more or less related to the Dutch language. This is relatively easy to do for most western countries: countries with English as the main language (US, UK, Australia) can be grouped together, countries with Germanic (German and Scandinavian) languages, a language family to which also the Dutch language belongs, can form a group, and Latin languages may be grouped together (French, Italian, Spanish). The German languages are closest to Dutch, followed by English and the Latin languages. But for the remaining countries it becomes increasingly difficult to classify countries by language, firstly because some languages show hardly any relation to languages in other countries, and secondly because for many countries there is no one to one relationship between language and country (for instance, in Africa language may be determined by tribe, rather than by nation). Therefore we end up by classifying the survey respondents in any of the following categories: English speaking, Germanic, Latin, Countries with English as 2nd official language, Asian countries, Middle East, Africa, and Eastern Europe. ${ }^{17}$ To exploit more information about individual countries, we add distance measures, as discussed in the next section. We include measures for linguistic distance (based on the language that someone grew up speaking), geographical distance, and genetic distance.

Table 1 identifies migrants from Turkey and Suriname as the largest groups. Narrowing down the sample to individuals that are more attached to the labour market reduces the shares of migrants from Turkish and Asian origin and increases the share of migrants from

\footnotetext{
16 Immigration from Turkey started at the end of the 1960-s/beginning of the 1970-s, mostly by male labour migrants. Families followed. Migration from Morocco started somewhat later, from the 1970-s on. Suriname and Indonesia were former Dutch colonies. When Suriname became independent in 1975, a movement of migration to the Netherlands took place. Indonesia became independent in 1948, and a large share of Indonesian migrants is of older age. The Dutch Antilles is somehow still part of the Kingdom of the Netherlands. There is no specific year at which a large group of immigrants entered from the Dutch Antilles, but migration happened throughout the years. Most older Indonesian migrants learned Dutch in their country, but this will not generally hold for the younger generations. The Dutch language is still used in Suriname and the Dutch Antilles, but mainly as an official language. People among each other speak their own language and especially in Suriname different population groups speak different languages. The respondents from the 'other' non-western and western countries originate from a diversity of countries and we somehow need to classify them into larger groups.

17 The category 'Latin language' can be subdivided into western (mainly southern European) and nonwestern (South American) migrants. Migration from Eastern Europe happened more often after the fall of the Berlin wall, and after the admission of some Eastern European countries in the European Union. Also migration from Africa seems to be more recent, after the warfare in several areas.
} 
Suriname somewhat.

About $57 \%$ of the migrants reports to experience no speaking problems, whereas the share that experiences no reading problems is somewhat higher, $63.2 \% .{ }^{18}$ More detailed descriptives in Table A of the appendix by area of origin shows considerable variation by origin in an intuitively appealing ordering. For instance, $77 \%$ of migrants from a Germanic country report not to experience speaking problems, whereas for migrants from Asia the percentage is 22. The subsample of respondents attached to the labour market shows somewhat better outcomes for the literacy and fluency indicators. Note, though, that also education levels are higher for this subsample.

In our analysis, we use binary indicators for speaking and reading proficiency. These indicators, named 'speak' and 'read', take the value 1 for those who never have problems in speaking or reading, and is zero otherwise. Thus, we aggregate the two gradations of 'yes' when it comes to having troubles with speaking or reading Dutch.

Respondents are asked whether they speak Dutch at home or an other language, and if the latter holds, they are asked to report this other language. ${ }^{19}$ Around 70 percent of the migrants speak Dutch at home, which is a larger percentage than the percentage of migrants who never experience any troubles in speaking or reading Dutch. This suggests that there are people experiencing trouble in speaking Dutch who nevertheless speak Dutch at home. ${ }^{20}$ A further analysis with the information on speaking Dutch at home (appendix, Table B) reveals that speaking Dutch at home is not so heavily influenced by linguistic distance or country of origin. Education and age since migration are more important determinants. Speaking Dutch at home may also be more prevalent among couples of mixed origin.

\footnotetext{
18 For survey respondents from Dutch/Belgian origin these percentages are 92.1 and 90.6, respectively.

19 First, they are asked to choose from Arabic, Berber, German, Frisian, Indonesian, Turkish, Flemish, or 'other language'. If the answer is 'other language', they are asked to explicitly type the name of their language. Surprisingly, there were some Dutch born respondents who answered by saying they were speaking an other language than Dutch and who filled out some local Dutch dialect, that officially is not a language different from Dutch. There were also some respondents who filled out two languages, among which is Dutch. For the Dutch/Belgium born sample, 3.7 percent responds by saying they speak a dialect. The percentage gets smaller if we select on age and labour market attachment.

20 The data show that high (low) fluency does not necessarily lead to (not) speaking at home. For the entire sample of migrants, we find that 53 percent reports to have no problems in speaking Dutch and speak Dutch at home; 20 percent reports both to have problems in speaking Dutch and do not speak Dutch at home; 17.9 percent reports to speak Dutch at home, even though they experience problems sometimes; 9.2 percent never experience problems but do not speak Dutch at home.
} 
The remaining variables in our sample are more or less the usual demographic control variables. Couples with children are more prevalent among the subsample of migrants attached to the labour market, whereas the reverse holds for singles. Table 1 also shows the occupational status variable on basis of which the subsample of those attached to the labour market was made. Removing those who are taking care of the housekeeping causes a reduction in the share of women.

Education levels between countries are difficult to compare. Therefore, we only use a broad categorization of education levels where we distinguish four levels.

In the appendix, Table A, we discuss more detailed descriptives by the grouped countries

of origin. Among the migrants, there are relatively more respondents with only a primary level of education than among the natives. The fractions of respondents with the highest and lowest level of education show whether a country delivers more lower educated workers or higher educated knowledge workers. Interestingly, the share of low (high) skilled migrants from Turkey and Morocco is relatively high (low) compared to the native Dutch population.

\section{Linguistic distance and the language of origin}

In the previous section we described the construction of area of origin dummies based on the country of birth. The LISS survey provides more information about the language of origin than can be derived from the country of birth. The following question is included in the survey: "Which language or languages did you grow up speaking?" For various reasons, the answer to this question gives us important information. First, we are able to determine the language of origin, even for countries with no one-to-one correspondence between language and origin. Second, for migrants born in one of the Dutch colonies, we can determine whether they grew up speaking Dutch, an other language, or a combination of Dutch and an other language. For instance, we found that people from Suriname either grew up speaking Sranan Tongo, Hindustani, or Dutch. Third, for migrants who moved to the Netherlands at school age or younger, we can determine whether the migrant grew up speaking Dutch or the language of origin, or possibly both. This way, we can disentangle the impact of age at migration from the impact of growing up speaking Dutch. 
Since we cannot include a dummy variable for any language of origin, we seek to construct a measure for linguistic distance based on the survey information. Isphording and Otten (2011) used a measure for linguistic distance, described in Bakker et al. (2009) in an analysis of language proficiency of migrants in Germany with the GSOEP and found that it is a strong predictor for their language proficiency indicator. ${ }^{21}$ The linguistic distance is measured using a lexicostatistical approach. A list of 40 stable elements from a list of words that is commonly used in linguistics ${ }^{22}$ is compared between two languages to determine the distance measure. The distance measure is based on the "minimum total number of additions, deletions, and substitutions of symbols necessary to transform one word into another" (Bakker et al, 2009). This number is normalized by dividing it by the maximum necessary changes (thus, it becomes a fraction). Finally, a correction is made for arbitrary coincidences between words of different languages, based on the combinations of words from the 40 words list with different meaning. ${ }^{23}$ Holman (2011) provides software and a database to compute the distance measure between any pair of languages. ${ }^{24}$ If survey respondents only report one language in which they grew up speaking, the distance measure is based on that unique language. If the migrant reports both Dutch and a foreign language, we experiment with two values: one based on Dutch (distance is zero) and the other based on the foreign language (see results next section).

We will use linguistic distance as an instrument for language proficiency: we make the assumption that it only affects labour market outcomes via language proficiency. Country dummies for former Dutch colonies and age at migration are not used as exclusion restriction to prevent that linguistic distance would proxy for omitted variables. ${ }^{25}$ However, linguistic

\footnotetext{
${ }^{21}$ Adsera and Pytlikova (2012) use an alternative measure of linguistic distance, based on the language tree.

22 The Swadish list, see Bakker et al. (2009).

${ }^{23}$ After this final correction, the resulting number is not necessarily a fraction any longer, but it is unlikely to exceed 1 by much. Holman (2011), expresses it as a 'percentage' by multiplying it by 100 .

24 To give an impression of the values (expressed in 'percentages'): for German, we have 50.2, for English 63.22, Sranan Tongo (spoken in Suriname) 74.2, Papiamento (spoken at the Antilles) 90.51, Spanish 91.1, Russian 92.2, Standard Arabic 100, Mandarin 100.3, Turkish 102.33. Thus, we see that for languages far away from Dutch, the distance measures are relatively close together (with Spanish remarkably close to Russian), whereas for languages closer to Dutch, like German and English, the differences in the distance measure are relatively far apart. Thus, the distribution of distance measures will be skewed, as also noted by Isphording and Otten, (2011).

${ }^{25}$ In the next section we show that our linguistic distance measure has explanatory power for our language proficiency indicator, next to age at migration and area of origin dummies.
} 
distance would not be a valid instrument if it would proxy for other distances between the country of origin and the country of destination that do have a direct effect on labour market outcomes. Chiswick and Miller (2001) include geographic distance as an indicator for language proficiency. We will also include an indicator for geographical distance, based on the shortest distance between the capital cities of the countries. ${ }^{26}$ Spolaore and Wacziarg (2009) and Ashraf and Galor (2012) address the impact of genetic distance and, respectively, genetic diversity, on differences in economic development between countries. If linguistic distance correlates with genetic distance, whereas the latter potentially affects economic outcomes, our exclusion restriction will be violated if we do not correct for genetic distance. Spolaore and Wacziarg (2009) made data on genetic distance available and we use this information in the estimation. ${ }^{27}$

\section{Determinants of fluency and literacy}

Chiswick (2007) discusses the relevant determinants of language proficiency in terms of the 3 E's: exposition, education, and economic incentives. Using our data for migrants in the age range older than 22 and younger than 65 (Table 1) we analyze the various determinants for our fluency indicator. Results for literacy turned out not to be fundamentally different and are presented in the appendix, where we also present a sensitivity analysis for the subsample of migrants attached to the labour force.

Table 2 shows Probit regressions results for fluency (dependent variable is 'speak', see Table 1). All presented standard errors allow for correlation in unobserved errors across time for the same individual (clustering). ${ }^{28}$ We gradually add more regressors to gain insight in the

\footnotetext{
${ }^{26}$ It should be noted that the linguistic distance measure by Bakker et al. (2009) is purely based on a comparison of words in different languages. Geographical distance can be quite different even if linguistic distance is similar (as in the case of the UK and the US).

27 We refer to appendix in Spolaore and Wacziarg (2009) for all the technical details on measuring genetic distance. For European countries, there are only four different values for the measure of genetic distance, which would be picked up by our area of origin dummies. For countries at larger distance the genetic distance measure actually shows much more variation than the linguistic distance measure, which makes it interesting to see how genetic distance affects outcomes. Ashraf and Galor (2012) explain how genetic diversity spread across the world, leading to a spread of genetic diversity that cannot simply be approximated by geographic distance.

28 Note that in this part of the analysis we use a Probit model, rather than a random effects probit model. Since this is a single equation analysis, the gain of adding random effect would be efficiency of the estimator,
} 
differential impact of various determinants of fluency. Starting with the origin dummies, with Asia as a reference group, the coefficient estimates show a ranking that is largely in accordance with the expectations: immigrants from (former) Dutch colonies (Suriname, Indonesia, and Dutch Antilles) have a better fluency, and also immigrants from German/Scandinavian origin, with languages related to Dutch, do relatively well. Immigrants with English and Latin languages follow. For immigrants from the Middle East, Morocco, Eastern Europe, and with English as a second language, there is no evidence that their fluency is better than the reference category Asia. The bottom of Table 2 shows the log-likelihood value and the Pseudo R-squared. The latter indicates that the origin indicator explains about $10 \%$ of the fluency indicator. The origin indicators are area of origin fixed effects that can absorb the impact of linguistic differences, but also the size of the migrants group in the destination country, and other potential differences.

Next, we add to the origin fixed effects the linguistic distance. ${ }^{29}$ We used information about the language someone grew up speaking to assign the value of the linguistic distance, which can be more detailed, or differ, from the information about the country of origin. Survey respondents can report multiple languages in which they grew up speaking, among which can be Dutch. We experimented with two linguistic distance variables. The values of the variables are the same for respondents reporting one language. The first variable (labelled 'Linguistic Distance' in Table 2) is set to Dutch if Dutch is among the languages that someone grew up speaking, while the second variable (labelled 'Linguistic Dist. (foreign)' in the Table) is set to the distance to the foreign language. Table 2 shows that both variables have a significant negative impact on fluency with a coefficient of comparable size. However, adding the first variant increases the R-squared from 0.10 to 0.21 , while for the second the R-squared becomes 0.17 . Therefore, we continued with the first variant. ${ }^{30}$

provided that the random effects structure holds. We rather present the possibly less efficient but more robust probit model with corrected standard errors. Once we present the two equations models in the next section, we allow for random effects, since random effects allow us to identify unobserved individuals specific correlation between proficiency and the economic outcome of interest.

29 Numerically we expressed the linguistic distance as a 'fraction' (see discussion section 3).

30 Other alternatives we tried were including a dummy variable indicating whether Dutch is among the languages someone grew up speaking and adding linguistic distance squared. The squared effect was not significant, whereas the dummy adds flexibility, but in the final specification, with all variables added, it did not add to the explanation in terms of the R-squared. To avoid the weak instruments problem (see Bound et al. (1995), we do not include the squared effect and the dummy in our final specification. 
Linguistic distance may not be a good exclusion restriction for labour market outcomes if it proxies for other distance measures between the country of origin and the country of destination. In section 3 we discussed the geographic distance and the genetic distance (using data from Spolaore and Wacziarg (2009)) as alternative distance measures. We base this distance information on the country of birth of the migrant and included the distance measure in the regression for fluency. Both indicators have a negative, but insignificant effects on fluency, while the coefficient of the linguistic distance variable is not affected. We nevertheless will keep the variables in the analysis, as they may still affect labour market outcomes, even if they do not affect proficiency.

Adding education (with higher and university education as reference category) shows that migrants with the lowest education level tend to have more problems in speaking Dutch. This is in line with education being one of the three E's affecting language proficiency.

The sixth regression adds the age of migration and its square. Age of migration is computed by subtracting the number of years that the migrant has been in the Netherlands from the age of the migrant. Chiswick and Miller (2001) also include this variable in their analysis, and predict that age of migration has a negative effect on language proficiency. The Pseudo R-squared and the log-likelihood value both show that the age at migration has a relatively big impact on the explanation of our fluency indicator: adding the age of migration and its square increases the Pseudo R-squared from 0.22 to $0.34 .{ }^{31}$ It is interesting to see that age at migration still has a relatively big impact on language proficiency, given the fact that we have already included information about migrants who grew up speaking Dutch, incorporated in our linguistic distance variable.

In the next column, we add age and gender. Age had a positive effect on fluency, but its coefficient does not affect so much the impact of age at migration. ${ }^{32}$ In the literature there is

\footnotetext{
31 In order to address the question whether age at migration merely approximates the difference between migrants who entered the Netherlands during youth, and therefore were educated in the Dutch schooling system, and migrants who entered during adulthood we did an analysis with a selected subsample of migrants who entered at a later than 12 (and therefore did not attend primary school in the Netherlands) and another analysis with a subsample of migrants who entered at age older than 18 (and thus did not attend secondary school in the Netherlands). We found a similar pattern as for the entire sample (a significant negative effect of age at migration and a small positive squared effect). The impact of age at migration on the pseudo R-squared is still substantial, but smaller, also because the impact of area of origin has a relatively bigger impact for those who entered at adulthood.

32 We also included age squared in a regression, but its effects was not significant.
} 
a discussion on whether or not to separate the analysis for men and women, since men and women may have different incentives for learning a language, especially if women are less attached to the labour market. The dummy indicator for female gender is not significant. ${ }^{33}$ Table 2 continues with a regression where we included variables for household composition. Notably the impact of children got attention in the literature: on the one hand, children may stimulate the fluency of parents, as they learn the language quickly at school, while on the other hand, the children may serve as translators for their parents, such that the parents themselves exercise the language less actively. Moreover, there may be a differential impact by gender. We included the number of children, as well as indicators for household type (couples without children, couples with children, lone parents, other households, and singles as reference category). The fluency of lone parents seems to be significantly lower than for other household types. The dummies for other household types are not significant. A likelihood ratio test confirms joint significance of the variables added, but the Pseudo R-squared does not show a large explanatory impact of these five variables on our language fluency indicator. Not reported is a regression which includes cross effects of the family indicators with gender. The value of the likelihood ratio test statistic for testing the joint significance of the cross effects with gender is 5.8, indicating that we cannot reject that there are no gender specific household composition effects.

Next we add an indicator for speaking Dutch at home. It is likely that speaking Dutch at home happens more often among couples of mixed origin. Chiswick (2007) notices that exposure to a language, for instance by speaking the language at home, helps in improving upon the fluency. The coefficient of speaking Dutch at home is significant at the $5 \%$ level. ${ }^{34}$

\footnotetext{
${ }^{33}$ Not reported here are regressions where we included cross effects for female gender and other variables. We included cross effects of female with the indicators Turkish and Moroccan origin, as these countries are dominantly Islamic, and the position of women may be different in these countries. We did not find any significant effects. Later we report on cross effects of gender with indicators for household composition.

${ }^{34}$ If speaking at home is an important determinant of exposure, it may be interesting to see which other variables correlate with the decision to speak at home. Therefore, we ran a probit regression with 'speaking Dutch at home' as the dependent variable. Results are in Table B in the appendix. We see that the ordering of areas of origin found in the fluency regressions, changed for 'speaking Dutch at home'. Especially Turkish migrants are less likely to speak at home. Suriname migrants are more likely to speak at home. For the remaining we do not see a clear ordering of areas of origin, as opposed to the fluency regressions. Linguistic distance has a negative effects while also age at migration has a negative impact and lower educated speak Dutch at home less often. Women speak Dutch at home more often. We also included cross effects of the gender dummy with family composition. These cross effects show that men in couples with children more often speak Dutch at home, but there is also an off-setting effect of the number of children: men speak less
} 
Finally, we included dummies for the degree of urbanization. A priori, the effect of urbanization is not signed: in an urban area migrants may easier meet Dutch speaking people which increases exposure to Dutch, while on the other hand in urban areas there may be a larger concentration of migrants from the same area of origin, which may decrease contacts with the native Dutch. The reference category in the regression is 'not urban'. None of the urban dummies is significant, although it is interesting to note that we spot kind of a U-shaped pattern: migrants in moderately urban areas do worst in terms of speaking fluency, but they do better the more or less urban is their area. Since none of the coefficients is significant, we should be very careful in drawing any conclusions from this result.

Table $\mathrm{C}$ in the appendix shows some sensitivity analyses. The left part shows regression results for the literacy indicator in our sample. The overall picture is the same. Differences are that education has a somewhat more pronounced effect, and that the influence of linguistic distance is smaller. Table A showed that migrants less often report problems with reading than with speaking, while for the native Dutch in the sample it is the other way around. We therefore consider the fluency indicator as the more reliable indicator of proficiency, as it requires more active skills of the migrant. The right side of Table $\mathrm{C}$ shows results for fluency, but with a restricted sample of respondents that are attached to the labour market. Results are also comparable to the findings in Table 2. An exception is that we now find a positive impact of the female gender.

\subsection{Additional instruments}

Linguistic distance, based on language that someone grew up speaking, is our main instrument. The regressions in Table 2 showed that it was a strong predictor of our proficiency indicator and at the same time it is plausible that it does have an impact on labour market outcomes exclusively via destination language proficiency, provided that sufficient controls that correlate with linguistics distance are included to explain the labour market outcomes.

From the LISS survey we selected two answers to statements about personality. The survey question is "How accurately each statement describes you?". Answers can be selected from five response categories in increasing order. The selected statements are "I have a rich often Dutch at home the larger is their number of children. 
vocabulary" and "I am quick to understand things". Table 3 shows the response. ${ }^{35}$ We construct dummy variables for the response categories, and on basis of the response we merged the lower two categories for the vocabulary question and the lower three for the other. The resulting lower categories are the reference categories.

Table 4 shows regression results that includes the variables. Coefficient estimates are significantly different from zero, showing that respondents confirming to have a rich vocabulary and to be quick to understand things are less likely to have problems in speaking Dutch.

The statement "I have a rich vocabulary" is not (meant to be) about the Dutch language, but if migrant respondents interpret it as such, it may by itself be an indicator of destination language proficiency, rather than a predictor. Therefore, we tried another alternative instrument based on the following statement presented to the respondents: "It is difficult for a foreigner to be accepted in the Netherlands while retaining his/her own culture". Response could take place in five categories, ranging from "fully disagree" to "fully agree". 36 The response to the question may indicate the willingness or ability to integrate in the Dutch society. ${ }^{37}$ In the regression in Table 4 we merged the opinions "fully disagree" and "disagree" to one category "disagree". Dummies for the other categories were not different from the base so we omit them all to reduce the weak instruments problem. ${ }^{38}$ We see that respondents who disagree tend to have a higher score on language proficiency. We again see that the Pseudo R2 also is higher than in regression without these instruments.

\section{$5 \quad$ Language proficiency and jobs}

We empirically analyze whether a poor proficiency of the Dutch language may lead to migrants performing jobs which do not match their education and skill level, leading to lower satisfaction. We use subjective information on job suitability and satisfaction (section 5.3)

\footnotetext{
35 The observation number is somewhat lower than our initial sample, due to the fact that different sections of the LISS survey are sent out and responded to in different months of the year.

${ }^{36}$ We added the category "missing" as we found that response to the politics and values section of the survey was lower for respondents with lower proficiency.

${ }^{37}$ We found that migrants from Turkish or Moroccan origin (mostly Islamic), as well as Africans, indicated more often that it was difficult to be accepted in the Netherlands, whereas the opposite holds for migrants from western countries.

38 So it is "disagree" versus the rest.
} 
and objective information about professional level (section 5.4).

\subsection{Subjective information on educational match and job satisfac- tion}

The survey contains subjective questions to collect information about the match between education, skills and the job. The first question is about education:

"Please indicate on a scale from 0 to 10 how your highest level of education suits the work that you now perform",

with zero indicating "does not at all suit my work" and ten indicating "suits my work perfectly". A similar question is asked for knowledge and skills:

"Please indicate on a scale from 0 to 10 how your knowledge and skills suit the work you do."

A final question that we use in our analysis is

"Can you indicate on a scale from 0 to 10 whether your knowledge and skills create any problems in fulfilling your position"

with zero indicating "very serious problems" and ten indicating "no problems at all". All these questions are asked to people with a paid job at the moment of the interview.

As far as job satisfaction is concerned, information about the following aspects is collected and used in our analysis:

"How satisfied are you with:
a) your wages or salary"
b) the type of work that you do"
c) your working hours"
d) your career so far"

Respondents could answer by indicating a number in the range of zero to ten, ranging from "not at all satisfied" to "fully satisfied". Table D in the appendix shows sample frequencies of the outcomes, also by gender. 


\subsection{Econometric specification}

The structure of the data collected this way suggests the use of an ordered regression framework. But there are three important issues we need to address. First, in our data we observe an indicator of language proficiency, but we need to acknowledge that the language proficiency itself is a latent variable. Second, unobserved individual specific effects that influence language proficiency may also have an impact on labour market outcomes. Third, we wish to fully exploit the panel nature of our data and control for unobserved individual effects. These issues are combined in the following model specification. Define $l_{i t}^{*}$ as a latent variable indicating language proficiency, whereas $l_{i t}$ is a binary indicator for it (like the indicator 'speak' in our data). Then we may define the equation

$$
l_{i t}^{*}=z_{i t}^{\prime} \beta+m_{i}+\epsilon_{i t} \text { with } l_{i t}=\iota\left(l_{i t} *>0\right)
$$

with $z_{i t}$ a vector of observable characteristics, uncorrelated with $m_{i}$ and $\epsilon_{i t}$, which are individual specific and idiosyncratic (zero mean) random variables, ${ }^{39}$ with $E m_{i}^{2}=\sigma_{m}^{2}$ and $E \epsilon_{i t}^{2}=1$. Let $r_{i t}$ denote one of the job suitability or job satisfaction indicators, and let $r_{i t}^{*}$ be an underlying latent variable.

$$
r_{i t}^{*}=\alpha l_{i t}^{*}+g_{i t}^{\prime} \gamma+\theta_{i}+v_{i t}
$$

with

$$
r_{i t}=j \text { if } c_{j}<r_{i t}^{*} \leq c_{j+1}, j=0, \ldots, 10
$$

with $c_{0}=-\infty$ and $c_{11}=+\infty$. In (2) $g_{i t}$ is a vector of observable characteristics, uncorrelated with $\theta_{i}$ and $v_{i t}$, which are again (zero mean) random variables, with $E \theta_{i}^{2}=\sigma_{\theta}^{2}$ and $E v_{i t}^{2}=1$. We allow for $E m_{i} \theta_{i}=\sigma_{m \theta} \neq 0$ and $E \epsilon_{i t} v_{i t}=\sigma_{\epsilon v} \neq 0$ with corresponding correlation coefficients $\rho_{m \theta}$ and $\rho_{\epsilon v} .{ }^{40}$ The correlation $\rho_{m \theta}$ is identified because of the panel nature of our data. Identification of $\rho_{\epsilon v}$ relies on instrumental variables and exclusion restrictions. As

\footnotetext{
${ }^{39}$ Due to the limited year to year variation in the language proficiency indicators $l_{i t}$ it makes no sense to think about fixed effects estimation.

${ }^{40}$ Note that (2) includes the latent language proficiency $l_{i t}^{*}$, rather than the binary indicator $l_{i t}$, a procedure also followed by Dustmann and Van Soest (2001).
} 
discussed in section 4, our prime instrument is linguistic distance based on the language that someone grew up speaking. We discussed some additional instruments that can be used for sensitivity analyses. Equations (1) and (2) will be estimated simultaneously for all labour market outcomes. ${ }^{41}$

\subsection{Results job suitability and satisfaction}

We estimated different model variants. The first specification is a simplification of the model in equation (2): we ignore potential correlation in unobservables between language proficiency and the labour market outcomes, and we simply plug in the fluency indicator $l_{i t}$ at the right hand side, ignoring that this variable is an indicator of an underlying latent language proficiency level. The first two columns of Table 5 show the regression coefficients $(\alpha$ in the notation of equation (2)) for this model, which is labelled as the 'naive model'. ${ }^{2}$ The model is estimated for all observations, men and women pooled, as well as for men and women separately. In the first column we did not include age at migration among the regressors and the results show evidence of positive correlations between the proficiency indicator and the job suitability measures, notably for men. We also find a positive correlation between the proficiency indicator and satisfaction, again notably for men and strongest for satisfaction with work type and career. However, excluding age at migration is not a legitimate exclusion restriction as, in general, this variable is very likely to influence labour market outcomes, and once we add age at migration to the naive model (2nd column of Table 5) significance of the language proficiency indicator largely disappears. Some evidence remains that women with a higher fluency experience less problems in performing their job. From now on in all the subsequent specifications age at migration and its square are included among the regressors. While discussing the model in (2) and (1) we argued that it is important to correct for correlation in unobservables and that the variable that we observe for fluency is just an indicator of an underlying latent proficiency level.

\footnotetext{
41 A simpler alternative is to first estimate equation (1) and use first stage estimates to estimate model (2), conditional on the errors of (1). The overall fit will be worse, though, and standard errors of the second stage still need to be corrected for the first stage.

${ }^{42}$ For reasons of conciseness we do not display the complete regression results. Table E in the appendix present the full regression results for the variant in which men and women are pooled, including the age at migration.
} 
The subsequent results in Table 5 are obtained with the simultaneous equation model. We estimated variants with and without random effects. Identification of correlation in random effects between the language proficiency and labour market outcomes comes from the panel nature of our data. This means that the variant without random effects leans more heavily on the exclusion restrictions and the instruments. We present estimates with four sets of instruments. The first contains linguistic distance, the next adds the responses to the statements about having a rich vocabulary and being quick to understand things, the third replaces the statement on having a rich vocabulary by the statement about the difficulty to be accepted as a foreigner, whereas in the final specification we drop the important information on linguistic distance, retaining the instruments based on the statements of having a rich vocabulary and being quick to understand things. By presenting results with several combinations of instruments we aim to check for the robustness of the outcomes. Table 5 again shows the coefficient estimate of parameter $\alpha$ in (2). The Appendix contains Tables with the complete regression results for equation (2) and the coefficients of the error structure. All these equations are estimated simultaneously with equation (1). For reasons of conciseness we omitted results for equation (1) since we have already discussed the results of determinants of language proficiency in section 4. Another difference between the estimates without and with random effects is that the model without random effects the language proficiency equation is completely gender specific, whereas in the random effects estimation we pooled men and women (like in the analysis in section 4). The Tables in the Appendix show the complete set of variables that are included in the equations. To minimize the possibility of measuring a spurious effect of language proficiency on labour market outcomes, we include the country of birth fixed effects, ${ }^{43}$ we include the measures for geographic and genetic distance, age at migration and its square, and variables for household composition. Thus, excluded are the instruments listed in Table 5, together with the variable dutch spoken at home. ${ }^{44}$

\footnotetext{
43 A higher level of aggregation of categories was used, since we are estimating with less observation than in section 4: middle east and English as a second language were merged to the Asian reference group, and we do not make a distinction between Latin western and non-western countries, on basis of the results of section 4. We also aggregated family composition by including a dummy for couples versus the remaining household type, as section 4 showed little impact of family composition. The number of children is maintained.

44 Results were not sensitive to the inclusion or exclusion of the variable Dutch spoken at home.
} 
Robust among all estimation results obtained with different instruments is the coefficient estimate of fluency on satisfaction with work type, suggesting that a higher fluency level leads to job types with a higher level of satisfaction. Separate estimation for men and women show that this effect is attributed to men. Estimates of fluency on the satisfaction with career and the fit of skills to work lose precision when the linguistic distance variable is dropped from the instrument set (see final two columns of Table 5), but they still show a $10 \%$ significant impact for men. A positive coefficient estimate of language proficiency on the fit between education and work is found for men as long as the linguistic distance measure is included. The outcome variable that shows most variation across instrument sets is the response to the statement that there are no problems with knowledge and skills in performing the current job. For women we find a positive impact of language proficiency on this statement for the second through fourth set of instruments, whereas an insignificant negative effect is found for the first set.

In conclusion we can say that the simultaneous models notably find effects of fluency for men, especially for satisfaction with work type, satisfaction with career, and the fit between ability and work. A positive effect of fluency for men is also found for the fit between education and work, as long as linguistic distance is included as an instrument. Results (not exposed here) with linguistic distance as an instrument were also robust to a more flexible specification with linguistic distance, its square, and a separate dummy variable for whether Dutch was among the language(s) someone grew up with. Results were also robust to more flexible specifications in age at migration: we added dummy variables for age at migration below six (meaning that the migrant followed primary and subsequent education in the Netherlands), age at migration below 12 (meaning that secondary and subsequent education was followed in the Netherlands), and age at migration below 18. Apparently the quadratic in age at migration was flexible enough.

\subsection{Language proficiency and professional level}

The analysis so far considered the direct effect of destination language proficiency on subjective outcomes of job satisfaction and indicators for job suitability, and we notably found a robust effect of fluency on the satisfaction with the type of work. The type of work may 
be related to the professional level of the job, which is a more objective measure of job type. We do an analysis in two steps: we first check how the subjective satisfaction and suitability indicators are related to professional level by including professional levels in ordered probit regressions for the satisfaction and suitability indicators. Next, we analyze the impact of language proficiency on the professional level. Since basically anybody is able to perform semi- or unskilled manual work, irrespective of the education, we narrow down the analysis to the question whether migrants with a lower language proficiency level are more likely to end up in a manual job. In the analysis we will again allow for unobservable correlation between proficiency and the probability to end up in such a job.

Table $\mathrm{L}$ in the appendix shows the various professional levels that are distinguished in the LISS questionnaire. We show sample percentages, both for native Dutch and for migrants, in the age range 22 to 65 , for which also the language proficiency indicator is observed. At the top of the labour market, we see a relatively (compared to the natives) high representation of migrants in higher academic professions. ${ }^{45}$ It is likely that for this group, Dutch language skills are of minor importance for their job characteristics, especially if they work at universities or multinational companies. But the higher educated is a small and specific group, also among the natives. Among higher supervisory professions, the migrants show smaller sample frequencies than the Dutch, and actually for almost all intermediate level professions, ranging from intermediate academic down to skilled and supervisory manual work, we see lower sample frequencies of migrants, compared to the native Dutch. The reverse holds for the lower three categories in the table, consisting of semi-skilled and unskilled manual work and agrarian professions. Adding them together, we see a much larger representation of migrants among these professional levels. In general, there will be a strong correlation between education level and professional level, so it is imaginable that part of the higher prevalence of migrants among manual workers can be attributed to differences in educational attainment. But language proficiency may also be a determinant.

In the first step the dummy variables for the professional levels were included in an ordered probit analysis of job satisfaction and job suitability, taking the semi-skilled, unskilled manual

\footnotetext{
45 Note, though, that the Table shows unweighted sample frequencies, so we should be careful in using them for drawing conclusions for the population as a whole. Population weights are not provided by LISS.
} 
work, and agrarian professions as one reference category. Tables $\mathrm{M}$ through $\mathrm{O}$ in the appendix show the estimation results (for both genders pooled, and men and women separately). For satisfaction with career and satisfaction with work time we see that, both for men and for women, most professional levels lead to a higher satisfaction than the manual reference category. We also find a better fit of education and the job, and of knowledge and skills and the job if the professional level is higher than manual. For men, we do not find much effect of professional level on satisfaction with wage, except that migrants with a higher academic profession are more satisfied with their wage than migrants with manual professions. For women we find a somewhat stronger relation between professional level and satisfaction with wage. For men, we find no relation between the professional level and satisfaction with work time, whereas women with an intermediate professional level seem to be more satisfied than manual workers. For men we do not find that migrants with a higher professional level have more or less problems in performing their job than migrants with a manual profession, whereas women with a higher academic profession seem to experience more problems in performing their job than women in manual professions. Over all, the impression is that if there is any relation between job satisfaction and professional level, migrants in manual jobs are less satisfied.

The second step is to analyze whether there is a relationship between language proficiency and having a manual profession. Also in carrying out this analysis, it is important to correct for possible endogeneity and correlation in unobservables: the information about Dutch language proficiency may proxy for other skills and abilities of the migrant that influence the probability of ending up in a manual profession.

Table 6 shows the estimation results. ${ }^{46}$ The table shows univariate regressions, where the indicator 'speak' is simply plugged in among the right hand side variables, both ignoring that it is an indicator of an underlying latent proficiency level and ignoring possible correlation in unobservables. The simultaneous estimation estimates are obtained by estimating a two equations system, conform the equations (2) and (1), with the only difference that now we have a binary indicator as a labour market outcome, rather than a ordered outcome. ${ }^{47}$ We

\footnotetext{
${ }^{46}$ For the simultaneous equations, we again omit results for the language proficiency equation.

47 We do not present random effects estimates, exploiting the panel nature. The wave to wave within individual variation in manual work turned out to be so small that it is not possible to identify random
} 
only present results in which we used the linguistic distance measure is used as an instrument (along with Dutch spoken at home). ${ }^{48}$ The univariate model shows a negative parameter estimate of fluency in the equation for the probability of having a manual job. Estimation by gender shows that this effect is attributed to men. In the simultaneous estimation the parameter estimate becomes less precise, but is still significant at the $10 \%$ level. Moreover, we find that the correlation coefficient between the equations for language proficiency and the probability of ending up in a manual job, $\rho$ is not significantly different from zero. Therefore, we also estimated the model with $\rho$ restricted to zero ${ }^{49}$ and found that the in the parameter of fluency became more precise (significantly different from zero at the $5 \%$ level) whereas, moreover, the likelihood ratio test statistic for testing the hypothesis $\rho=0$ took the value 0.86 (in the estimation for men), such that the null hypothesis is not rejected.

In conclusion we may say that at the least we find a negative correlation between the probability of ending up in a manual job for men only, and this negative correlation remains but becomes less precise if we allow for simultaneity between the two processes. The lower precision may be due the limited variation across time in the manual job state within individuals. Restricting the correlation in unobservables to zero is not rejected by the likelihood ratio test and the restricted model shows a more precise parameter of fluency on the probability of having a manual job.

\subsection{Reason for different outcomes by gender?}

The previous analyses showed that, both for subjective and objective measures of job level outcomes, we mainly found an impact of language proficiency for men, but not for women. Since in general, labour market participation rates for men are higher than for women, we did an additional analysis to check whether there is a difference between men and women as far as the impact of fluency on selection into employment is concerned. We did an effects. The variance of the random effect in the manual work equation, which also measures the within individual correlation across time, grew very large during the maximization procedure.

${ }^{48}$ Results with the other instruments showed a more precise parameter estimate for fluency, but may be less plausible as exclusion restriction, since education is an important determinant of ending up in a manual job, and the regressions in Table 4 showed some evidence of collinearity between education and the other instruments.

${ }^{49}$ Note that this is different from the univariate estimates in Table 6 , because with $\rho$ equal to zero we still allow for the latent nature of language proficiency. 
analysis with employment as the outcome variable, both for a full sample (i.e. measuring employment versus non-employment) and a sample of individuals attached to the labour market (i.e. measuring employment versus unemployed participants). For men we did not find an impact of language proficiency on employment for any sample. ${ }^{50}$ For women, we found a positive impact on employment for both subsamples if we estimate an employment equation simultaneously with an equation for proficiency. ${ }^{51}$ Thus, it seems that for women language proficiency plays a more pronounced role in selection into employment, so once selected into employment proficiency does not have an additional impact on job level outcomes. Men seek to enter employment, irrespective of their language proficiency, and within employment outcomes for job level seem to move together with proficiency.

\section{Conclusions}

The analysis in the paper addresses whether a lower proficiency of the destination country's language leads to lower level and less satisfactory jobs, given the other background characteristics of the worker. We used a Dutch panel survey to analyze the issue for migrants in the Netherlands. The analysis of the determinants of language proficiency using the proficiency indicators available in the data shows intuitively appealing results. In particular, migrants with a language of origin that is more closely related to the Dutch language attain a higher proficiency level of the destination language. We use a measure for linguistic distance that comes from the linguistic literature, combined with survey information about the language(s) that migrants grew up speaking. We also included geographic and genetic distance measures between the country of origin and destination to avoid that the measure for linguistic distance proxies other aspects.

We pay particular attention to some econometric issues. The survey information on proficiency is modelled as an indicator of a latent underlying proficiency level, and we allow for correlation in unobservables that may both drive the proficiency level and the labour market

\footnotetext{
50 For reasons of conciseness we do not show any additional tables results.

51 When we estimated a single equation for employment, including the binary fluency indicator at the right hand side, thereby ignoring simultaneity and measurement issues, we found a positive impact on employment (versus non-employment), but no effect of employment versus unemployed participants.
} 
outcome. For the identification of this correlation we rely both on the panel structure of our data in a random effects specification, but we also do a detailed sensitivity analysis with various sets of variables that are used as exclusion restrictions. Maybe our most important instrument is the measure for linguistic distance, combined with survey information on the languages that someone grew up speaking. Other instruments came from survey questions about personality (the individual's self-reported vocabulary and quickness to understand things), the individual's self-reported opinion about difficulty to be accepted in the Netherlands, and speaking Dutch at home. The precision of estimates of the effects of proficiency on the subjective outcomes obtained with different instruments differs somewhat but overall results point in the same direction.

We analyzed subjective information about the match between education and job level as well the satisfaction with various job aspects and also. The impact of fluency on labour market outcomes is found to be most obvious for men and nearly absent for women. Higher fluency leads to more satisfaction with work type and career, and also to a better fit between education level and job, and knowledge/skills and job.

The difference in outcomes between men and women is also found when we analyze the professional level as a (more objective) labour outcome. Men with a lower fluency are more likely to end up in a manual job. For women, no statistically significant relation could be detected. An analysis of the relation between the (objective) professional levels and the subjective labour market outcomes on job satisfaction and job match showed that migrants in manual job are in general less satisfied with various aspects of work.

We did a final analysis to see whether outcomes were the differences in outcomes between men and women could be explained by selection into employment. We found that the employment status of men was no affected by language proficiency whereas women with a higher fluency were more likely to be employed.

\section{References}

Adsera, A, and M. Pytlikova (2012), The role of language in shaping international migration, Norface Migration Discussion Paper No. 2012-14. 
Ashraf, Q. and O. Galor (2012), The "Out of Africa" hypothesis, human genetic diversity, and comparative Economic development, working paper.

Bakker, B, C.H. Brown, P. Brown, D. Egorov, A. Grant, E.W. Holman, R. Mailhammer, A. Müller, V. Velupillai, S. Wichman (2009), Adding typology to lexicostatistics: a combined approach to language classification, Linguistic Typology, Vol. 13, nr. 1, pp. 169-181.

Bound, D., J.A. Jaeger, and R.M. Baker (1995), Problems with instrumental variables estimation when the correlation between the instruments and the endogenous explanatory variable is weak, Journal of the American Statistical Association, Vol. 90, no. 430, pp. 443-450.

Chevalier, A. (2003), Measuring overeducation, Economica, Vol. 70, pp. 509-531.

Chiswick, B.R. (2007), The Economics of Language for Immigrants: An Introduction and Overview, Julian Simon Lecture Series, IZA, Bonn.

Chiswick, B.R, and P.W. Miller (1995), The Endogeneity between Language and Earnings: International Analyses, Journal of Labor Economics, Vol. 123, No. 2, pp. $246-288$.

Chiswick, B.R, and P.W. Miller (2001), A Model of Destination-Language Acquisition: Application to Male Immigrants in Canada, Demography, Vol. 38, No. 3, pp. 391-409.

Chiswick, B.R. and P.W. Miller (2011), Negative and positive assimilation, skill transferability, and linguistic distance, IZA Discussion Paper No. 5420.

Dustmann, C. (1994), Speaking Fluency, Writing Fluency and Earnings of Migrants, Journal of Population Economics, Vol. 7, pp. 133-156.

Dustmann, C, and F. Fabbri (2003), Language proficiency and labour market performance of immigrants on the UK, Economic Journal, Vol. 113, No. 489, pp. 695-717.

Dustmann, C, and A. van Soest (2001), Language Fluency and Earnings: Estimation with Misclassified Language Indicators, The Review of Economics and 
Statistics, Vol. 83, No. 4, pp. 663-674.

Gonzales, P.S. (2010), The impact of education and host language skills on the labor market outcomes of immigrants in Spain, Ivestigaciones de Economia de la Educacion 5, pp. 798-824.

Holman, E.W. (2011), Programs for calculating ASJP distance matrices (version 2.1).

http://email.eva.mpg.de/ wichmann/software.htm

http://email.eva.mpg.de/ wichmann/listss15.zip

Holman, E.W, S. Wichmann, C.H. Brown, V. Velupillai, A. Müller, P. Brown, and D. Bakker (2008), Explorations in automatic language comparison. Folia Linguistica, Vol. 42, pp. 331-354.

Isphording, I.E, and S. Otten (2011), Linguistic distance and the language fluency of immigrants, Ruhr Economic Papers \# 274

Mavromaras, K., McGuinnes, S., O’Leary, N., Sloane, P., and Wei, Z. (2010), Job mismatches and labour market outcomes: Panel evidence on Australian university graduates, National Institute of Labour Studies, Flinders University, Working Paper No. 163.

Scherpenzeel, A. (2009), Start of the LISS panel: Sample and recruitment of probability-based internet panel, CentERdata, Tilburg.

Spolaore, E. and R. Wacziarg (2009), The diffusion of development, Quarterly Journal of Economics, Vol. 124, No. 2, pp. 469-529.

\section{A Descriptive statistics by ethnic group}

Table A shows some descriptives by ethnic group. We focus on the table selected on the basis of age, shown in the second pane of Table A. The first two lines compare the native Dutch/Belgium with the entire group of migrants. Among the native Dutch/Belgium, the percentages of respondents that report no problems in speaking and reading Dutch are 92 and 90. For the migrants, these percentages are much lower, 57 and 63. Remarkable is that 
for the foreign born the percentage reporting no problems in reading is higher than that for speaking, possibly indicating that reading is more like a passive activity in which the reader can determine his or her own pace. There is considerable heterogeneity in the responses depending on the group of origin. The ranking is in line with the expectation: people from former Dutch colonies report relatively often to have no problems with speaking. For Suriname, Indonesia, and the Dutch Antilles the percentages are 85, 78, and 68. Among people German origin, whose language belongs to the same family as Dutch, 78 percent reports not to experience any speaking problems. For respondents with English and Latin languages of origin the speaking performance is still a little above the average for migrants (59 per cent without any speaking problems for both groups). People from Asia experience speaking problems most often: only 21 percent reports no problems. Below average is also the speaking performance of the Turkish, Moroccan, people from countries in which English is a 2nd language, Eastern Europe, and Africa, with respective percentages of 44, 42, 41, 44, and 50 for the absence of speaking problems. People from the Middle East report in only 31 percent of the cases to have no speaking problems. People from Indonesia, Germany, and other western countries report to only belong to the Dutch population more often than the average migrant. People from Turkey, Suriname, and Asia most often report to belong to an other population group than the Dutch. People from Morocco, and the Dutch Antilles relatively often report that they belong both to the Dutch population and to another population. People from (former) Dutch colonies relatively often only have the Dutch nationality. Relatively few of the people from Turkey, English and Latin speaking countries report to have only the Dutch nationality. People from Turkey, Morocco, and the Middle East relatively often report to have both the Dutch nationality and an other nationality. It is also interesting to look at the lowest and highest education level by origin. Do immigrants mainly have education levels, or are they highly educated knowledge workers? For some groups, we see an over-representation of low educated people, compared to the Dutch respondents. The percentage of low educated is especially high for the Turkish and Moroccan group. Whereas only 6 percent of the Dutch report to belong to the lowest education group, the percentages are 27 and 30 for the Turkish and Moroccan. At the same time, the percentages of highly educated are relatively low for these groups. Among the Dutch 34 percent is highly educated, 
whereas these percentages are 13 and 16 for immigrants from Turkey and Morocco. Some groups show a higher percentage of lower educated than the Dutch, but the percentages of highly educated is comparable to the Dutch. This holds for immigrants from Suriname, people with an Latin language, and English as a second language. People from German countries and Asia report both a lower percentage of low educated and a higher percentage of highly educated. Also people from English speaking countries, the Middle East and Eastern Europe show a fairly large percentage of higher educated, but their share of lower educated is somewhat higher compared to the Dutch. If we interpret membership of a sports-club or a cultural club as an indicator of social integration, then we see that immigrants from western countries are relatively often a member of a sports-club. Notably people from Turkey and the Middle East are underrepresented as far as membership of a sports-club is concerned, followed by migrants from Indonesia, Africa, Morocco, the Dutch Antilles and Asia. People from English speaking countries, Morocco, and Africa, are relatively often a member of a cultural club, people from Turkey, the Dutch Antilles, Eastern Europe, and Indonesia are underrepresented. 
Table 1: Sample of Migrants

Sample percentages and means of pooled sample

\begin{tabular}{|c|c|c|}
\hline Variable & $22<$ age $<65$ & $\begin{array}{l}\text { Attached to } \\
\text { lab. market } \\
\quad N T=943\end{array}$ \\
\hline \multicolumn{3}{|l|}{ Origin (language group/area) } \\
\hline Turkey & 12.2 & 11.0 \\
\hline Morocco & 7.6 & 7.0 \\
\hline Dutch Antilles & 9.3 & 9.2 \\
\hline Suriname & 11.2 & 13.0 \\
\hline Indonesia & 5.5 & 5.5 \\
\hline German/Scandinavian (language area) & 9.7 & 9.1 \\
\hline English (language area) & 8.0 & 8.1 \\
\hline Latin languages & 10.2 & 10.4 \\
\hline English as official (2nd) language & 3.6 & 3.8 \\
\hline Asia & 4.6 & 3.9 \\
\hline African & 3.5 & 3.9 \\
\hline Eastern Europe & 9.4 & 9.2 \\
\hline Middle East & 5.1 & 5.7 \\
\hline \multicolumn{3}{|l|}{ Troubles speaking Dutch? } \\
\hline yes, often/don't speak Dutch & 4.4 & 3.6 \\
\hline yes, sometimes & 38.6 & 36.9 \\
\hline no, never & 57.0 & 59.5 \\
\hline \multicolumn{3}{|l|}{ Trouble understanding reading? } \\
\hline yes, often/don’t speak Dutch & 4.4 & 3.7 \\
\hline yes, sometimes & 32.8 & 30.3 \\
\hline no, never & 63.2 & 66.0 \\
\hline Speak (never problems) & 57.0 & 59.5 \\
\hline Read (never problems) & 63.2 & 66.0 \\
\hline \multicolumn{3}{|l|}{ Speak Dutch at home or other language? } \\
\hline Dutch at home & 68.9 & 72.1 \\
\hline Dutch dialect & 0.5 & 0.4 \\
\hline Two languages & 0.4 & 0.1 \\
\hline Female & 58.0 & 50.2 \\
\hline \multirow[t]{2}{*}{ Age (mean, std) } & 43.0 & 41.8 \\
\hline & $(10.6)$ & $(9.4)$ \\
\hline
\end{tabular}


Table 1 (continued): Sample of Migrants

Sample percentages and means of pooled sample

\begin{tabular}{|c|c|c|}
\hline Variable & $22<$ age $<65$ & $\begin{array}{l}\text { Attached to } \\
\text { lab. market }\end{array}$ \\
\hline Observations: & $N T=1303$ & $N T=943$ \\
\hline \multicolumn{3}{|l|}{ Household type } \\
\hline Single & 16.4 & 17.4 \\
\hline Couple without children & 23.9 & 20.6 \\
\hline Couple with children & 47.4 & 49.8 \\
\hline Lone parent & 10.9 & 10.6 \\
\hline Other household type & 1.5 & 1.6 \\
\hline \multirow[t]{2}{*}{ Number of household members (mean, std) } & 2.9 & 2.9 \\
\hline & $(1.3)$ & $(1.3)$ \\
\hline \multirow[t]{2}{*}{ Number of children (mean, std) } & 1.1 & 1.1 \\
\hline & $(1.1)$ & $(1.0)$ \\
\hline Has partner & 71.2 & 70.4 \\
\hline \multicolumn{3}{|l|}{ Urbanisation } \\
\hline Extremely urban & 26.0 & 25.7 \\
\hline Very urban & 33.7 & 34.2 \\
\hline Moderately urban & 23.0 & 24.5 \\
\hline Slightly urban & 12.2 & 10.4 \\
\hline Not urban & 5.0 & 5.2 \\
\hline \multicolumn{3}{|l|}{ Occupational status } \\
\hline In paid employment & 57.2 & 79.8 \\
\hline Works/assists in family business & 1.5 & 2.0 \\
\hline Autonomous professional, freel, self-empl. & 4.4 & 6.0 \\
\hline Job seeker following job loss & 5.5 & 7.6 \\
\hline First time job seeker & 1.2 & 1.9 \\
\hline Exempted from job seeking following job & 1.0 & \\
\hline Attends school or is studying & 4.5 & \\
\hline Takes care of the housekeeping & 11.8 & \\
\hline Is pensioner, [voluntary] early retirem & 3.8 & \\
\hline Has (partial) work disability & 5.8 & \\
\hline Performs unpaid work while retaining ben. & 0.6 & 0.9 \\
\hline Performs voluntary work & 1.3 & 1.8 \\
\hline Does something else & 1.2 & \\
\hline Is too young to have an occupation & 0.1 & \\
\hline \multicolumn{3}{|l|}{ Education level } \\
\hline Primary education & 12.7 & 9.5 \\
\hline Lower vocational/professional training & 20.3 & 17.7 \\
\hline Higher sec and middle voc/prof training & 32.8 & 34.9 \\
\hline Higher voc/prof training, university & 34.2 & 37.9 \\
\hline
\end{tabular}


Table 2: Probit regressions speaking fluency for sample of migrants, $22<$ age $<65, N T=1303$

\begin{tabular}{|c|c|c|c|c|c|c|c|c|}
\hline Variable & Coef. & Std. & Coef. & Std. & Coef. & Std. & Coef. & Std. \\
\hline Turkey & $0.68^{*}$ & 0.36 & $1.08^{* *}$ & 0.39 & $0.98^{* *}$ & 0.34 & $0.82^{*}$ & 0.43 \\
\hline Moroccan & 0.51 & 0.37 & $0.69^{*}$ & 0.41 & $0.79^{* *}$ & 0.36 & 0.41 & 0.48 \\
\hline Dutch Antilles & $1.20^{* *}$ & 0.37 & $0.97^{* *}$ & 0.40 & $1.12^{* *}$ & 0.35 & $0.93^{* *}$ & 0.40 \\
\hline Suriname & $1.85^{* *}$ & 0.38 & $1.28^{* *}$ & 0.42 & $1.45^{* *}$ & 0.39 & $1.20^{* *}$ & 0.46 \\
\hline Indonesia & $1.55^{* *}$ & 0.42 & $1.01^{* *}$ & 0.45 & $0.97^{* *}$ & 0.45 & $1.11^{* *}$ & 0.45 \\
\hline German/Scand. & $1.53^{* *}$ & 0.38 & $1.32^{* *}$ & 0.41 & $0.95^{* *}$ & 0.38 & $0.97^{*}$ & 0.52 \\
\hline English & $1.00^{* *}$ & 0.38 & $0.94^{* *}$ & 0.40 & 0.61 & 0.37 & 0.69 & 0.48 \\
\hline Latin, western & $1.06^{* *}$ & 0.39 & $1.51^{* *}$ & 0.42 & $1.17^{* *}$ & 0.38 & $1.20^{* *}$ & 0.51 \\
\hline Latin, nonwestern & $1.06^{* *}$ & 0.38 & $1.20^{* *}$ & 0.42 & $0.78^{* *}$ & 0.39 & $1.21^{* *}$ & 0.45 \\
\hline English 2nd lang. & 0.60 & 0.44 & 0.45 & 0.47 & 0.31 & 0.38 & 0.43 & 0.47 \\
\hline Africa & $0.73^{*}$ & 0.44 & $0.99^{*}$ & 0.51 & 0.57 & 0.47 & $0.90^{*}$ & 0.53 \\
\hline Eastern Europe & $0.62^{*}$ & 0.37 & $1.09^{* *}$ & 0.40 & $0.74^{* *}$ & 0.35 & 0.78 & 0.49 \\
\hline Middle East & 0.34 & 0.40 & $0.78^{*}$ & 0.43 & 0.45 & 0.38 & 0.56 & 0.49 \\
\hline Linguistic Distance & & & $-1.41^{* *}$ & 0.15 & & & $-1.41^{* *}$ & 0.15 \\
\hline Linguistic Dist. (foreign) & & & & & $-1.47^{* *}$ & 0.23 & & \\
\hline Geographic distance & & & & & & & -0.04 & 0.03 \\
\hline Genetic distance & & & & & & & -0.23 & 2.11 \\
\hline \multicolumn{9}{|l|}{ Prim. Education } \\
\hline \multicolumn{9}{|l|}{ Lower voc./prof. } \\
\hline \multicolumn{9}{|l|}{ Higher sec./middle voc. } \\
\hline \multicolumn{9}{|l|}{ Age at migration } \\
\hline \multicolumn{9}{|l|}{ Sqr. Of age at migr. } \\
\hline \multicolumn{9}{|l|}{ Age } \\
\hline \multicolumn{9}{|l|}{ Female } \\
\hline \multicolumn{9}{|l|}{ \# Children } \\
\hline \multicolumn{9}{|l|}{ couple without children } \\
\hline \multicolumn{9}{|l|}{ Couple with children } \\
\hline \multicolumn{9}{|l|}{ Lone parent } \\
\hline \multicolumn{9}{|l|}{ Other household } \\
\hline \multicolumn{9}{|l|}{ Speak Dutch at home } \\
\hline \multicolumn{9}{|l|}{ Extremely urban } \\
\hline \multicolumn{9}{|l|}{ Very urban } \\
\hline \multicolumn{9}{|l|}{ moderately urban } \\
\hline slightly urban & & & & & & & & \\
\hline Intercept & $-0.78^{* *}$ & 0.32 & -0.12 & 0.37 & 0.40 & 0.37 & 0.26 & 0.50 \\
\hline Likelihood Value & -800.7 & & -702.3 & & -738.3 & & -700.7 & \\
\hline Pseudo R2 & 0.10 & & 0.21 & & 0.17 & & 0.21 & \\
\hline $\begin{array}{l}\text { Reference categories dummy } \\
\text { Not urban; Both Dutch an } \\
* * / * \text { : significant at } 5 / 10 \%\end{array}$ & $\begin{array}{l}\text { variables: } \\
\text { other nat } \\
\text { vel; stand }\end{array}$ & Asia; & $\begin{array}{l}\text { Sher pro } \\
\text { Both Di } \\
\text { s adjust }\end{array}$ & $\begin{array}{l}\text { ssiona } \\
\text { ch an } \\
\text { for } \mathrm{cl}\end{array}$ & $\begin{array}{l}\text { vocation } \\
\text { other po } \\
\text { stering. }\end{array}$ & $\begin{array}{l}1 \text { train } \\
\text { ulatiol }\end{array}$ & $\begin{array}{l}\text { gg, univer } \\
\text { group. }\end{array}$ & \\
\hline
\end{tabular}


Table 2: Probit regressions speaking fluency for sample of migrants (continued)

$22<$ age $<65, N T=1303$

\begin{tabular}{|c|c|c|c|c|c|c|}
\hline Variable & Coef. & Std. & Coef. & Std. & Coef. & Std. \\
\hline Turkey & $0.94^{* *}$ & 0.44 & 0.35 & 0.37 & 0.41 & 0.36 \\
\hline Moroccan & 0.51 & 0.48 & 0.26 & 0.40 & 0.28 & 0.40 \\
\hline Dutch Antilles & $1.01^{* *}$ & 0.41 & $1.37^{* *}$ & 0.33 & $1.38^{* *}$ & 0.32 \\
\hline Suriname & $1.27 * *$ & 0.46 & $1.48^{* *}$ & 0.39 & $1.37^{* *}$ & 0.39 \\
\hline Indonesia & $1.16^{* *}$ & 0.45 & $0.81^{* *}$ & 0.38 & 0.55 & 0.38 \\
\hline German/Scand. & $0.92^{*}$ & 0.52 & $1.03^{* *}$ & 0.46 & $1.02^{* *}$ & 0.46 \\
\hline English & 0.65 & 0.48 & 0.46 & 0.41 & 0.38 & 0.41 \\
\hline Latin, western & $1.23^{* *}$ & 0.51 & $0.99^{* *}$ & 0.45 & $0.95^{* *}$ & 0.45 \\
\hline Latin, nonwestern & $1.24^{* *}$ & 0.44 & $1.18^{* *}$ & 0.36 & $1.10^{* *}$ & 0.34 \\
\hline English 2nd lang. & 0.47 & 0.46 & 0.32 & 0.35 & 0.33 & 0.34 \\
\hline Africa & $1.02^{*}$ & 0.54 & $1.04^{*}$ & 0.57 & $1.07^{*}$ & 0.60 \\
\hline Eastern Europe & 0.72 & 0.49 & 0.67 & 0.42 & $0.70^{*}$ & 0.42 \\
\hline Middle East & 0.53 & 0.50 & 0.67 & 0.42 & 0.61 & 0.44 \\
\hline Linguistic Distance & $-1.39 * *$ & 0.15 & $-0.80^{* *}$ & 0.17 & $-0.76^{* *}$ & 0.18 \\
\hline \multicolumn{7}{|l|}{ Linguistic Dist. (foreign) } \\
\hline Geographic distance & -0.04 & 0.03 & -0.04 & 0.03 & -0.03 & 0.03 \\
\hline Genetic distance & -0.84 & 2.08 & -2.29 & 2.09 & -2.56 & 2.24 \\
\hline Prim. Education & $-0.59^{* *}$ & 0.20 & $-0.62^{* *}$ & 0.22 & $-0.65^{* *}$ & 0.23 \\
\hline Lower voc./prof. & -0.21 & 0.17 & $-0.44^{* *}$ & 0.18 & $-0.49^{* *}$ & 0.18 \\
\hline Higher sec./middle voc. & -0.09 & 0.14 & -0.21 & 0.15 & $-0.19^{* *}$ & 0.15 \\
\hline Age at migration & & & $-0.93^{* *}$ & 0.19 & $-0.92^{* *}$ & 0.19 \\
\hline Sqr. Of age at migr. & & & $0.08^{* *}$ & 0.04 & 0.07 & 0.04 \\
\hline Age & & & & & $0.20^{* *}$ & 0.07 \\
\hline Female & & & & & -0.02 & 0.13 \\
\hline \multicolumn{7}{|l|}{ \# Children } \\
\hline \multicolumn{7}{|l|}{ couple without children } \\
\hline \multicolumn{7}{|l|}{ Couple with children } \\
\hline \multicolumn{7}{|l|}{ Lone parent } \\
\hline \multicolumn{7}{|l|}{ Other household } \\
\hline \multicolumn{7}{|l|}{ Speak Dutch at home } \\
\hline \multicolumn{7}{|l|}{ Extremely urban } \\
\hline \multicolumn{7}{|l|}{ Very urban } \\
\hline \multicolumn{7}{|l|}{ moderately urban } \\
\hline \multicolumn{7}{|l|}{ slightly urban } \\
\hline Intercept & 0.41 & 0.49 & 1.75 & 0.46 & 1.00 & 0.51 \\
\hline Likelihood Value & -690.5 & & -591.3 & & -582.4 & \\
\hline Pseudo R2 & 0.22 & & 0.34 & & 0.35 & \\
\hline $\begin{array}{l}\text { Reference categories dumm } \\
\text { Not urban; Both Dutch a } \\
* * / * \text { : significant at } 5 / 10 \%\end{array}$ & $\begin{array}{l}\text { ofessional } \\
\text { Outch and } \\
\text { ted for clu }\end{array}$ & $\begin{array}{l}\text { vocatic } \\
\text { other } 1 \\
\text { stering }\end{array}$ & $\begin{array}{l}\text { nal traini } \\
\text { opulation }\end{array}$ & $\begin{array}{l}\text { g, uni } \\
\text { roup. }\end{array}$ & rsity; Sin & \\
\hline
\end{tabular}


Table 2: Probit regressions speaking fluency for sample of migrants (continued) $22<$ age $<65, N T=1303$

\begin{tabular}{|c|c|c|c|c|c|c|}
\hline Variable & Coef. & Std. & Coef. & Std. & Coef. & Std. \\
\hline Turkey & 0.46 & 0.35 & $0.63^{*}$ & 0.36 & $0.66^{*}$ & 0.37 \\
\hline Moroccan & 0.33 & 0.40 & 0.35 & 0.40 & 0.39 & 0.41 \\
\hline Dutch Antilles & $1.47^{* *}$ & 0.32 & $1.58^{* *}$ & 0.34 & 1.60 & 0.35 \\
\hline Suriname & $1.47^{* *}$ & 0.38 & $1.37^{* *}$ & 0.38 & $1.39^{* *}$ & 0.40 \\
\hline Indonesia & 0.56 & 0.38 & 0.56 & 0.38 & 0.54 & 0.38 \\
\hline German/Scand. & $1.07^{* *}$ & 0.46 & $1.01^{* *}$ & 0.46 & $1.00 * *$ & 0.47 \\
\hline English & 0.40 & 0.41 & 0.38 & 0.41 & 0.40 & 0.42 \\
\hline Latin, western & $1.00^{* *}$ & 0.45 & $0.88^{*}$ & 0.45 & $0.90^{*}$ & 0.46 \\
\hline Latin, nonwestern & $1.13^{* *}$ & 0.34 & $1.01^{* *}$ & 0.34 & $1.01^{* *}$ & 0.35 \\
\hline English 2nd lang. & 0.29 & 0.34 & 0.35 & 0.37 & 0.35 & 0.38 \\
\hline Africa & $1.08^{*}$ & 0.57 & $1.03^{*}$ & 0.57 & $1.08^{*}$ & 0.55 \\
\hline Eastern Europe & $0.71^{*}$ & 0.42 & 0.66 & 0.42 & $0.75^{*}$ & 0.43 \\
\hline Middle East & 0.65 & 0.43 & 0.66 & 0.45 & 0.64 & 0.46 \\
\hline Linguistic Distance & $-0.75^{* *}$ & 0.17 & $-0.63^{* *}$ & 0.18 & $-0.69 * *$ & 0.17 \\
\hline \multicolumn{7}{|l|}{ Linguistic Dist. (foreign) } \\
\hline Geographic distance & -0.03 & 0.03 & -0.02 & 0.03 & -0.02 & 0.03 \\
\hline Genetic distance & -2.46 & 2.21 & -2.73 & 2.23 & -2.74 & 2.21 \\
\hline Prim. Education & $-0.62^{* *}$ & 0.22 & $-0.56^{* *}$ & 0.23 & $-0.54^{* *}$ & 0.23 \\
\hline Lower voc./prof. & $-0.54^{* *}$ & 0.18 & $-0.53^{* *}$ & 0.18 & $-0.53^{* *}$ & 0.18 \\
\hline Higher sec./middle voc. & -0.18 & 0.15 & -0.16 & 0.15 & -0.17 & 0.16 \\
\hline Age at migration & $-0.98^{* *}$ & 0.18 & $-0.93^{* *}$ & 0.18 & $-0.95^{* *}$ & 0.18 \\
\hline Sqr. Of age at migr. & $0.07^{*}$ & 0.04 & $0.07^{*}$ & 0.04 & $0.08^{* *}$ & 0.04 \\
\hline Age & $0.21^{* *}$ & 0.07 & $0.16^{* *}$ & 0.07 & $0.18^{* *}$ & 0.07 \\
\hline Female & 0.05 & 0.13 & 0.01 & 0.13 & 0.00 & 0.13 \\
\hline \# Children & 0.03 & 0.09 & 0.06 & 0.09 & 0.07 & 0.10 \\
\hline couple without children & -0.15 & 0.20 & -0.17 & 0.20 & -0.13 & 0.20 \\
\hline Couple with children & -0.17 & 0.24 & -0.22 & 0.24 & -0.19 & 0.25 \\
\hline Lone parent & $-0.51^{*}$ & 0.31 & $-0.55^{*}$ & 0.31 & $-0.51^{*}$ & 0.31 \\
\hline Other household & -0.73 & 0.62 & -0.70 & 0.62 & -0.61 & 0.61 \\
\hline Speak Dutch at home & & & $0.55^{* *}$ & 0.13 & $0.54^{* *}$ & 0.13 \\
\hline Extremely urban & & & & & -0.17 & 0.35 \\
\hline Very urban & & & & & -0.31 & 0.33 \\
\hline moderately urban & & & & & -0.55 & 0.34 \\
\hline slightly urban & & & & & -0.13 & 0.36 \\
\hline Intercept & 1.07 & 0.53 & 0.73 & 0.56 & 0.96 & 0.66 \\
\hline Likelihood Value & -577.4 & & -562.7 & & -555.9 & \\
\hline Pseudo R2 & 0.35 & & 0.37 & & 0.38 & \\
\hline $\begin{array}{l}\text { Reference categories dumm } \\
\text { Not urban; Both Dutch a } \\
* * / * \text { : significant at } 5 / 10 \%\end{array}$ & $\begin{array}{l}\text { fessional/ } \\
\text { utch and } \\
\text { ed for clu }\end{array}$ & $\begin{array}{l}\text { ocatio } \\
\text { ther p }\end{array}$ & $\begin{array}{l}\text { al trainin } \\
\text { oulation }\end{array}$ & $\begin{array}{l}\text {, univ } \\
\text { coup. }\end{array}$ & sity; Sing & \\
\hline
\end{tabular}


Table 3: Descriptive statistics instrumental variables from Personality and Politics and Values section $22<$ age $<65, N T=1111$

\begin{tabular}{lccccc}
\hline Personality section & $\begin{array}{c}\text { very } \\
\text { inaccurate }\end{array}$ & $\begin{array}{c}\text { moderately } \\
\text { inaccurate }\end{array}$ & $\begin{array}{c}\text { in } \\
\text { between }\end{array}$ & $\begin{array}{c}\text { moderately } \\
\text { accurate }\end{array}$ & $\begin{array}{c}\text { very } \\
\text { accurate }\end{array}$ \\
\hline I have a rich vocabulary & 1.9 & 11.7 & 32.6 & 40.9 & 13.0 \\
I am quick to understand things & 0.2 & 3.8 & 22.7 & 53.5 & 19.9 \\
\hline \multicolumn{5}{l}{$\begin{array}{l}\text { Politics and Values section } \\
\text { It is difficult for a foreigner to be accepted in the Netherlands }\end{array}$} \\
$\begin{array}{l}\text { fully } \\
\text { disagree }\end{array}$ & disagree & in & agree & fully & missing \\
3.0 & 14.7 & between & \multicolumn{4}{c}{ agree } & 7.9 \\
\hline
\end{tabular}


Table 4: Probit regressions speaking fluency for sample of migrants including instrumental variables from "personality" and "politics and values" section $22<$ age $<65, N T=1111$

\begin{tabular}{|c|c|c|c|c|}
\hline Variable & Coef. & Std. & Coef. & Std. \\
\hline Turkey & 0.50 & 0.40 & 0.49 & 0.40 \\
\hline Moroccan & 0.19 & 0.44 & 0.15 & 0.43 \\
\hline Dutch Antilles & $1.38^{* *}$ & 0.37 & $1.43^{* *}$ & 0.37 \\
\hline Suriname & $1.61^{* *}$ & 0.41 & $1.73^{* *}$ & 0.40 \\
\hline Indonesia & 0.52 & 0.42 & 0.60 & 0.41 \\
\hline German/Scand. & $1.24^{* *}$ & 0.49 & $1.35^{* *}$ & 0.50 \\
\hline English & 0.63 & 0.43 & 0.71 & 0.44 \\
\hline Latin, western & $1.24^{* *}$ & 0.50 & $1.23^{* *}$ & 0.50 \\
\hline Latin, nonwestern & $1.32^{* *}$ & 0.40 & $1.31^{* *}$ & 0.39 \\
\hline English 2nd lang. & 0.35 & 0.37 & 0.28 & 0.37 \\
\hline Africa & $1.08^{*}$ & 0.64 & 0.95 & 0.64 \\
\hline Eastern Europe & $0.89 *$ & 0.47 & $0.86^{*}$ & 0.47 \\
\hline Middle East & $0.87^{*}$ & 0.51 & 0.78 & 0.51 \\
\hline Linguistic Distance & $-0.73^{* *}$ & 0.20 & $-0.74^{* *}$ & 0.19 \\
\hline Geographic distance & -0.03 & 0.03 & -0.04 & 0.03 \\
\hline Genetic distance & -0.84 & 2.20 & -0.48 & 2.17 \\
\hline Prim. Education & -0.28 & 0.28 & -0.43 & 0.28 \\
\hline Lower voc./prof. & -0.30 & 0.21 & $-0.41^{* *}$ & 0.20 \\
\hline Higher sec./middle voc. & 0.12 & 0.18 & 0.03 & 0.18 \\
\hline Age at migration & $-0.85^{* *}$ & 0.20 & $-0.90^{* *}$ & 0.20 \\
\hline Sqr. Of age at migr. & 0.03 & 0.04 & 0.05 & 0.04 \\
\hline Age & $0.24^{* *}$ & 0.07 & $0.24^{* *}$ & 0.07 \\
\hline Female & -0.05 & 0.14 & -0.08 & 0.14 \\
\hline \# Children & -0.86 & 1.17 & -0.87 & 1.16 \\
\hline couple without children & -0.21 & 0.22 & -0.22 & 0.21 \\
\hline Couple with children & 0.01 & 0.29 & -0.04 & 0.29 \\
\hline Lone parent & -0.39 & 0.36 & -0.39 & 0.36 \\
\hline Other household & -1.19 & 0.72 & $-1.26^{*}$ & 0.69 \\
\hline Rich vocabulary:in between & 0.26 & 0.17 & 0.25 & 0.17 \\
\hline Rich vocabulary: accurate & $0.69^{* *}$ & 0.17 & $0.70^{* *}$ & 0.18 \\
\hline Rich vocabulary:very accurate & $0.85^{* *}$ & 0.22 & $0.85^{* *}$ & 0.23 \\
\hline Quickly understand:accurate & $0.42^{* *}$ & 0.13 & $0.56^{* *}$ & 0.14 \\
\hline Quickly understand:very accurate & $0.60^{* *}$ & 0.19 & $0.85^{* *}$ & 0.18 \\
\hline foreigner diff. accepted:disagree & & & $0.41 * *$ & 0.14 \\
\hline Intercept & -0.20 & 0.66 & 0.23 & 0.66 \\
\hline Likelihood Value & -445.6 & & -455.1 & \\
\hline Pseudo R2 & 0.41 & & 0.40 & \\
\hline \multicolumn{5}{|c|}{$\begin{array}{l}\text { Reference categories dummy variables: Asia; Higher professional/vocational training, university; Single; } \\
\text { Not urban; Both Dutch and other nationality; Both Dutch and other population group. } \\
* * / * \text { : significant at } 5 / 10 \% \text { level; standard errors adjusted for clustering. }\end{array}$} \\
\hline
\end{tabular}




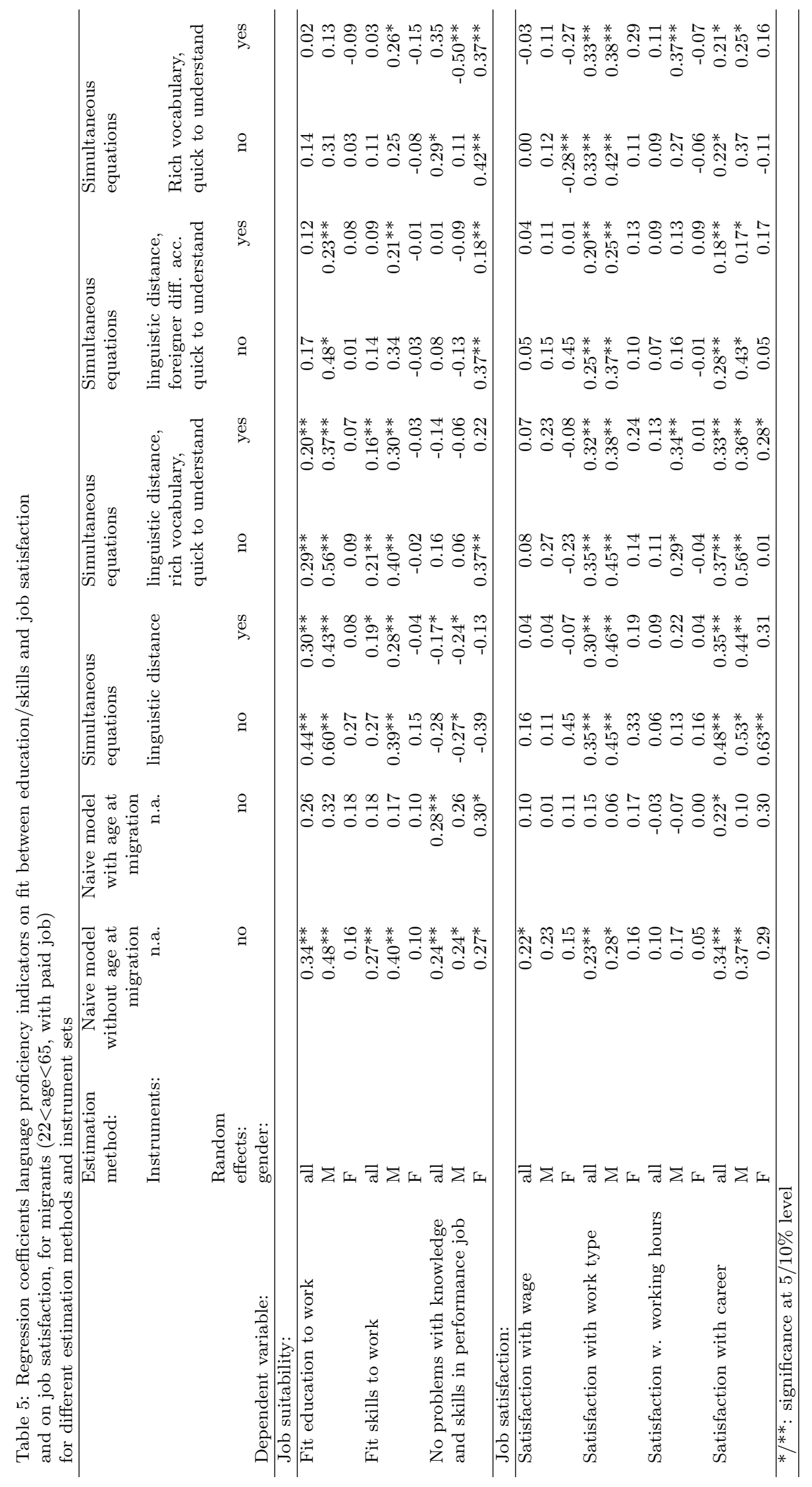




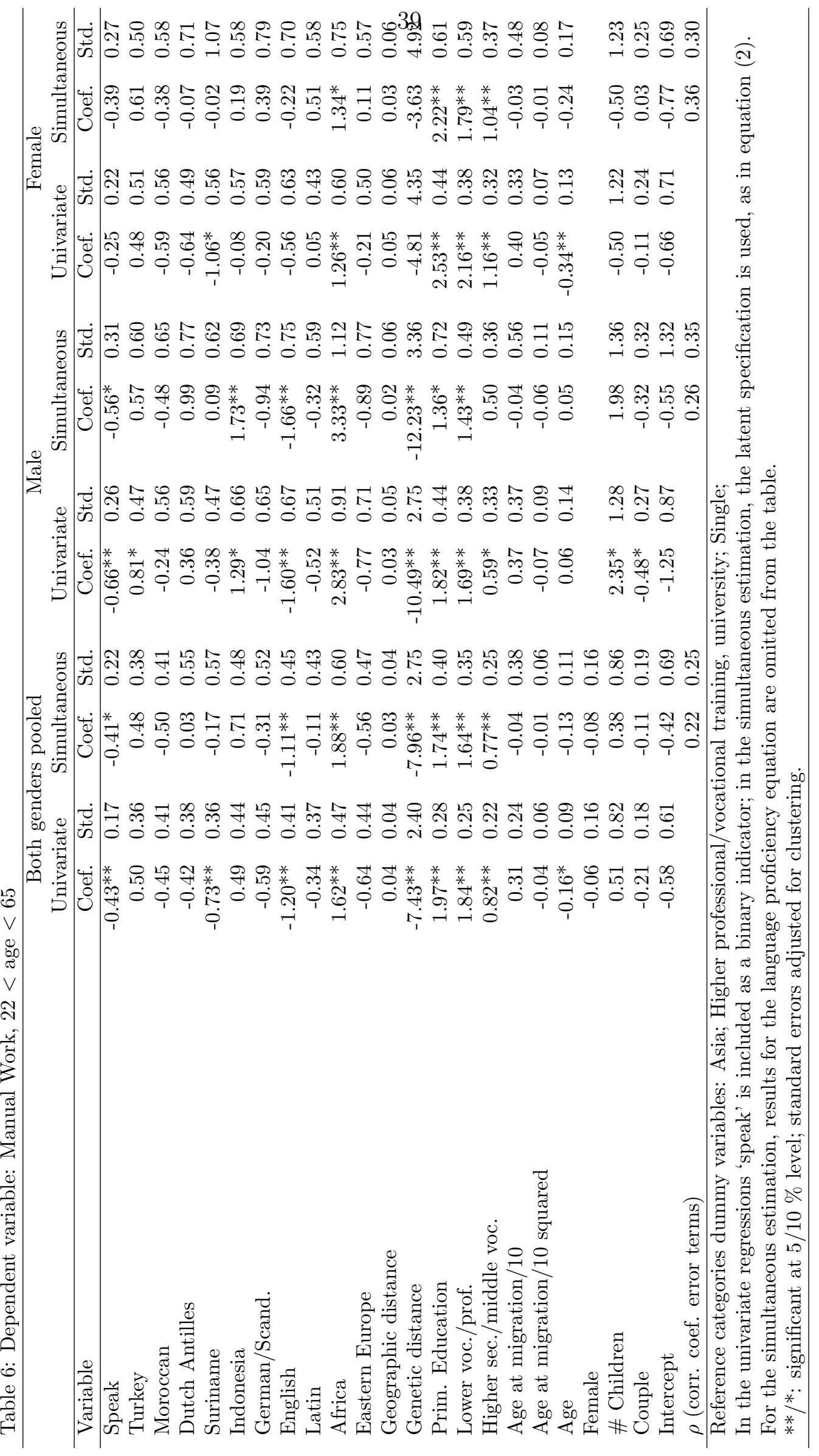




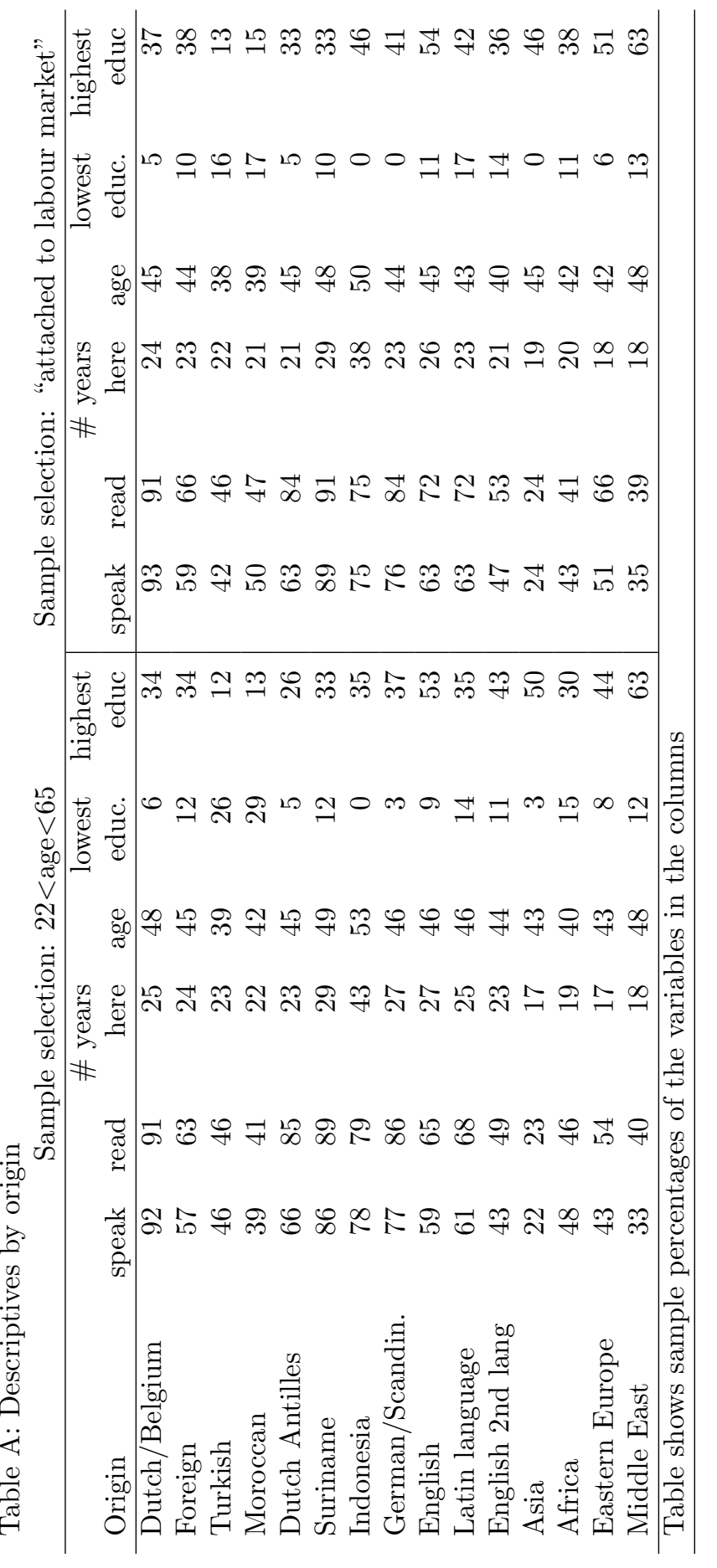


Table B: Probit regressions Dutch spoken at home by migrants $22<$ age $<65, N T=1303$

\begin{tabular}{lrrrr}
\hline Variable & Coef. & Std. & Coef. & Std. \\
\hline Turkey & $-1.02^{* *}$ & 0.41 & $-1.03^{* *}$ & 0.41 \\
Moroccan & -0.22 & 0.41 & -0.21 & 0.41 \\
Dutch Antilles & -0.43 & 0.38 & -0.46 & 0.38 \\
Suriname & $0.88^{* *}$ & 0.39 & $0.93^{* *}$ & 0.39 \\
Indonesia & 0.22 & 0.59 & 0.23 & 0.60 \\
German/Scand. & 0.24 & 0.46 & 0.24 & 0.46 \\
English & -0.15 & 0.41 & -0.12 & 0.41 \\
Latin, western & 0.54 & 0.50 & 0.51 & 0.50 \\
Latin, nonwestern & $0.78^{* *}$ & 0.39 & $0.79^{* *}$ & 0.39 \\
English 2nd lang. & $-0.61^{*}$ & 0.36 & $-0.61^{*}$ & 0.36 \\
Africa & 0.32 & 0.40 & 0.30 & 0.39 \\
Eastern Europe & 0.13 & 0.43 & 0.11 & 0.43 \\
Middle East & -0.05 & 0.44 & -0.04 & 0.44 \\
Linguistic Distance & $-0.73^{* *}$ & 0.18 & $-0.73^{* *}$ & 0.18 \\
Geographic Distance & -0.03 & 0.03 & -0.03 & 0.03 \\
Genetic distance & 0.90 & 1.50 & 1.15 & 1.52 \\
Prim. Education & $-0.35^{*}$ & 0.19 & $-0.34^{*}$ & 0.19 \\
Lower voc./prof. & -0.15 & 0.18 & -0.13 & 0.18 \\
Higher sec./middle voc. & -0.10 & 0.15 & -0.09 & 0.15 \\
Age at migration & $-0.71^{* *}$ & 0.19 & $-0.72^{* *}$ & 0.19 \\
Sqr. Of age at migr. & 0.06 & 0.04 & 0.06 & 0.04 \\
Age & $1.33^{* *}$ & 0.48 & $1.32^{* *}$ & 0.48 \\
Age squared & $-0.12^{* *}$ & 0.06 & $-0.12^{* *}$ & 0.06 \\
Female & $0.34^{* *}$ & 0.13 & 0.53 & 0.32 \\
\# Children & $-0.20^{* *}$ & 0.10 & -0.29 & 0.17 \\
couple without children & 0.14 & 0.20 & 0.12 & 0.28 \\
Couple with children & 0.35 & 0.26 & $0.67^{*}$ & 0.40 \\
Lone parent & 0.06 & 0.31 & -0.07 & 0.61 \\
Other household & -0.43 & 0.43 & 0.02 & 0.56 \\
Female $\times$ \# Children & & & -0.55 & 0.53 \\
Female $\times$ couple without children & & & -0.03 & 0.42 \\
Female $\times$ Couple with children & & & -0.78 & 0.81 \\
Female $\times$ Lone parent & & & 0.02 & 0.71 \\
Female $\times$ Other household & & & 0.11 & 0.20 \\
Intercept & -1.15 & 1.12 & -1.20 & 1.13 \\
\hline Likelihood Value & -565.2 & & -562.7 & \\
Pseudo R2 & 0.30 & & 0.30 & \\
\hline Rer & & & &
\end{tabular}

Reference categories dummy variables:

Asia; Higher professional/vocational training, university; Single.

**/*: significant at 5/10 \% level; standard errors adjusted for clustering. 
Table C: Probit regressions for literacy, $22<$ age $<65, N T=1303$

and fluency, subsample of migrants attached to the labour force, $N T=723$

\begin{tabular}{|c|c|c|c|c|}
\hline \multirow[b]{2}{*}{ Variable } & \multicolumn{2}{|c|}{ literacy } & \multicolumn{2}{|c|}{$\begin{array}{c}\text { subsample } \\
\text { fluency }\end{array}$} \\
\hline & Coef. & Std. & Coef. & Std. \\
\hline Turkey & 0.44 & 0.33 & 0.14 & 0.41 \\
\hline Moroccan & 0.41 & 0.37 & 0.18 & 0.46 \\
\hline Dutch Antilles & $1.95^{* *}$ & 0.29 & $1.47^{* *}$ & 0.39 \\
\hline Suriname & $1.99^{* *}$ & 0.35 & $1.54^{* *}$ & 0.45 \\
\hline Indonesia & $0.77^{* *}$ & 0.35 & 0.74 & 0.44 \\
\hline German/Scand. & $1.52^{* *}$ & 0.44 & 0.65 & 0.52 \\
\hline English & $0.73^{*}$ & 0.37 & 0.42 & 0.47 \\
\hline Latin, western & $1.20 * *$ & 0.44 & $0.89^{*}$ & 0.49 \\
\hline Latin, nonwestern & $1.32^{* *}$ & 0.30 & $1.27^{* *}$ & 0.38 \\
\hline English 2nd lang. & $0.56^{*}$ & 0.29 & 0.22 & 0.41 \\
\hline Africa & 0.70 & 0.50 & 0.90 & 0.58 \\
\hline Eastern Europe & $0.85^{* *}$ & 0.39 & 0.38 & 0.48 \\
\hline Middle East & 0.61 & 0.39 & 0.51 & 0.49 \\
\hline Linguistic distance & $-0.35^{* *}$ & 0.16 & $-0.74^{* *}$ & 0.21 \\
\hline Geographic distance & -0.04 & 0.03 & $-0.06^{*}$ & 0.03 \\
\hline Genetic distance & -0.50 & 1.91 & -3.23 & 2.42 \\
\hline Prim. Education & $-1.02^{* *}$ & 0.21 & $-0.68 * *$ & 0.27 \\
\hline Lower voc./prof. & $-0.68 * *$ & 0.18 & $-0.64^{* *}$ & 0.20 \\
\hline Higher sec./middle voc. & -0.04 & 0.15 & -0.18 & 0.17 \\
\hline Age at migration & $-0.81^{* *}$ & 0.18 & $-1.08 * *$ & 0.23 \\
\hline Sqr. Of age at migr. & $0.07^{*}$ & 0.04 & $0.10^{* *}$ & 0.05 \\
\hline Age & $0.22^{* *}$ & 0.07 & $0.21^{* *}$ & 0.08 \\
\hline Female & -0.06 & 0.13 & $0.32^{* *}$ & 0.14 \\
\hline \# Children & 0.03 & 0.09 & -0.08 & 0.12 \\
\hline couple without children & $-0.42^{* *}$ & 0.19 & -0.10 & 0.23 \\
\hline Couple with children & -0.26 & 0.23 & 0.02 & 0.28 \\
\hline Lone parent & -0.25 & 0.29 & $-0.68 * *$ & 0.34 \\
\hline Other household & $-1.05^{*}$ & 0.54 & -0.76 & 0.77 \\
\hline Intercept & 0.63 & 0.51 & $1.41^{* *}$ & 0.62 \\
\hline Likelihood Value & -585.1 & & -410.9 & \\
\hline Pseudo R2 & 0.32 & & 0.35 & \\
\hline
\end{tabular}

Reference categories dummy variables:

Asia; Higher professional/vocational training, university; Single.

**/*: significant at 5/10 \% level; standard errors adjusted for clustering. 
Table D: Response to job satisfaction and job suitability questions of migrants, $22<$ age $<65$, with paid job

\begin{tabular}{|c|c|c|c|c|c|c|c|}
\hline \multicolumn{8}{|c|}{ Both men and women: } \\
\hline $\begin{array}{l}\text { Response } \\
\text { category }\end{array}$ & $\begin{array}{r}\text { Fit education } \\
\text { and work }\end{array}$ & $\begin{array}{r}\text { Fit skills } \\
\text { work }\end{array}$ & $\begin{array}{r}\text { Job } \\
\text { performance }\end{array}$ & $\begin{array}{r}\text { Satisfaction } \\
\text { Wage }\end{array}$ & $\begin{array}{l}\text { Satisfaction } \\
\text { type of work }\end{array}$ & $\begin{array}{r}\text { Satisfaction } \\
\text { hours }\end{array}$ & $\begin{array}{r}\text { Satisfaction } \\
\text { career }\end{array}$ \\
\hline 0 & 12.4 & 5.6 & 0.6 & 4.5 & 2.9 & 0.7 & 2.1 \\
\hline 1 & 3.6 & 1.9 & 1.4 & 1.2 & 0.6 & 0.4 & 1.1 \\
\hline 2 & 5.6 & 1.8 & 1.0 & 4.5 & 1.3 & 2.3 & 2.0 \\
\hline 3 & 2.8 & 3.0 & 1.8 & 6.1 & 2.6 & 1.7 & 2.3 \\
\hline 4 & 6.6 & 4.7 & 3.2 & 6.3 & 2.0 & 2.4 & 3.3 \\
\hline 5 & 7.4 & 6.6 & 4.6 & 13.3 & 8.0 & 8.1 & 9.0 \\
\hline 6 & 11.7 & 10.2 & 5.5 & 13.8 & 9.3 & 11.3 & 14.3 \\
\hline 7 & 15.7 & 18.1 & 12.4 & 20.8 & 19.5 & 21.3 & 23.9 \\
\hline 8 & 17.9 & 26.4 & 20.4 & 19.5 & 28.1 & 27.6 & 26.3 \\
\hline 9 & 8.2 & 13.9 & 21.6 & 7.2 & 16.1 & 13.7 & 10.4 \\
\hline 10 & 8.2 & 7.8 & 27.7 & 3.0 & 9.7 & 10.4 & 5.3 \\
\hline Nobs & 728 & 728 & 726 & 694 & 701 & 700 & 700 \\
\hline \multicolumn{8}{|l|}{ Men only: } \\
\hline $\begin{array}{r}\text { Response } \\
\text { category }\end{array}$ & $\begin{array}{r}\text { Fit education } \\
\text { and work }\end{array}$ & $\begin{array}{r}\text { Fit skills } \\
\text { work }\end{array}$ & $\begin{array}{r}\text { Job } \\
\text { performance }\end{array}$ & $\begin{array}{r}\text { Satisfaction } \\
\text { wage }\end{array}$ & $\begin{array}{r}\text { Satisfaction } \\
\text { type of work }\end{array}$ & $\begin{array}{r}\text { Satisfaction } \\
\text { hours }\end{array}$ & $\begin{array}{r}\text { Satisfaction } \\
\text { career }\end{array}$ \\
\hline 0 & 9.3 & 4.4 & 0.3 & 3.2 & 2.0 & 0.3 & 1.4 \\
\hline 1 & 4.4 & 1.1 & 1.6 & 0.9 & 0.3 & 0.0 & 0.9 \\
\hline 2 & 4.1 & 1.6 & 1.4 & 3.5 & 1.1 & 2.3 & 2.3 \\
\hline 3 & 3.3 & 3.6 & 2.5 & 5.8 & 2.3 & 0.9 & 1.7 \\
\hline 4 & 6.3 & 3.6 & 2.7 & 6.3 & 2.3 & 3.4 & 4.0 \\
\hline 5 & 7.7 & 7.1 & 3.8 & 15.0 & 8.8 & 9.7 & 10.2 \\
\hline 6 & 13.7 & 8.7 & 5.5 & 13.0 & 10.2 & 10.0 & 14.7 \\
\hline 7 & 18.3 & 18.9 & 12.6 & 18.4 & 21.0 & 20.2 & 22.4 \\
\hline 8 & 18.3 & 29.0 & 17.5 & 19.6 & 24.9 & 28.8 & 24.4 \\
\hline 9 & 7.7 & 15.0 & 22.5 & 10.1 & 17.6 & 13.1 & 11.9 \\
\hline 10 & 7.1 & 7.1 & 29.6 & 4.3 & 9.6 & 11.4 & 6.2 \\
\hline Nobs & 366 & 366 & 365 & 347 & 353 & 351 & 353 \\
\hline \multicolumn{8}{|c|}{ Women only: } \\
\hline $\begin{array}{l}\text { Response } \\
\text { category }\end{array}$ & $\begin{array}{r}\text { Fit education } \\
\text { and work }\end{array}$ & $\begin{array}{r}\text { Fit skills } \\
\text { work }\end{array}$ & $\begin{array}{r}\text { Job } \\
\text { performance }\end{array}$ & $\begin{array}{r}\text { Satisfaction } \\
\text { Wage }\end{array}$ & $\begin{array}{l}\text { Satisfaction } \\
\text { type of work }\end{array}$ & $\begin{array}{r}\text { Satisfaction } \\
\text { hours }\end{array}$ & $\begin{array}{r}\text { Satisfaction } \\
\text { career }\end{array}$ \\
\hline 0 & 15.5 & 6.9 & 0.8 & 5.8 & 3.7 & 1.2 & 2.9 \\
\hline 1 & 2.8 & 2.8 & 1.1 & 1.4 & 0.9 & 0.9 & 1.4 \\
\hline 2 & 7.2 & 1.9 & 0.6 & 5.5 & 1.4 & 2.3 & 1.7 \\
\hline 3 & 2.2 & 2.5 & 1.1 & 6.3 & 2.9 & 2.6 & 2.9 \\
\hline 4 & 6.9 & 5.8 & 3.6 & 6.3 & 1.7 & 1.4 & 2.6 \\
\hline 5 & 7.2 & 6.1 & 5.3 & 11.5 & 7.2 & 6.6 & 7.8 \\
\hline 6 & 9.7 & 11.6 & 5.5 & 14.7 & 8.3 & 12.6 & 13.8 \\
\hline 7 & 13.0 & 17.4 & 12.2 & 23.1 & 18.1 & 22.4 & 25.4 \\
\hline 8 & 17.4 & 23.8 & 23.3 & 19.3 & 31.3 & 26.4 & 28.2 \\
\hline 9 & 8.8 & 12.7 & 20.8 & 4.3 & 14.7 & 14.3 & 8.9 \\
\hline 10 & 9.4 & 8.6 & 25.8 & 1.7 & 9.8 & 9.5 & 4.3 \\
\hline Nobs & 362 & 362 & 361 & 347 & 348 & 349 & 347 \\
\hline
\end{tabular}




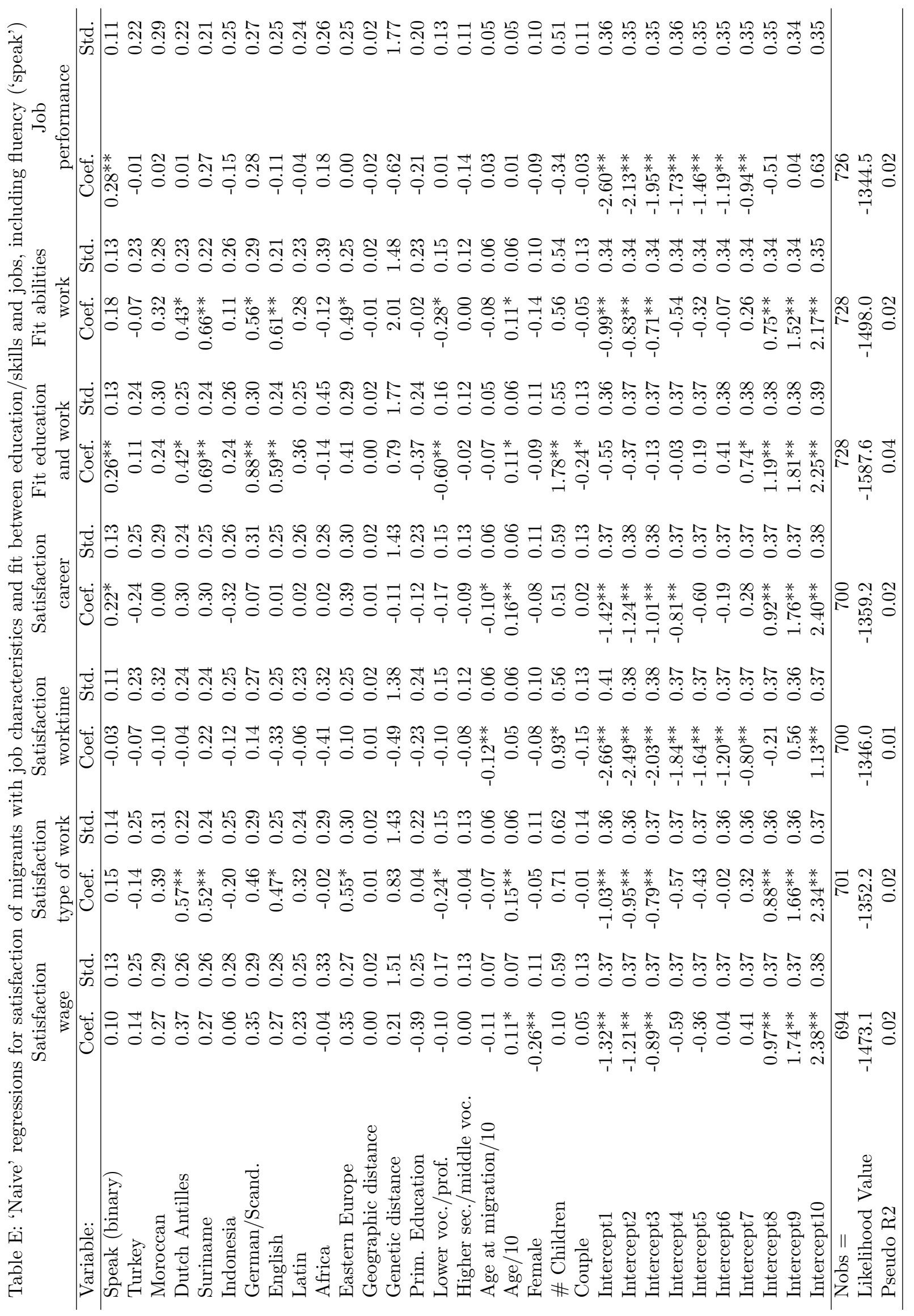




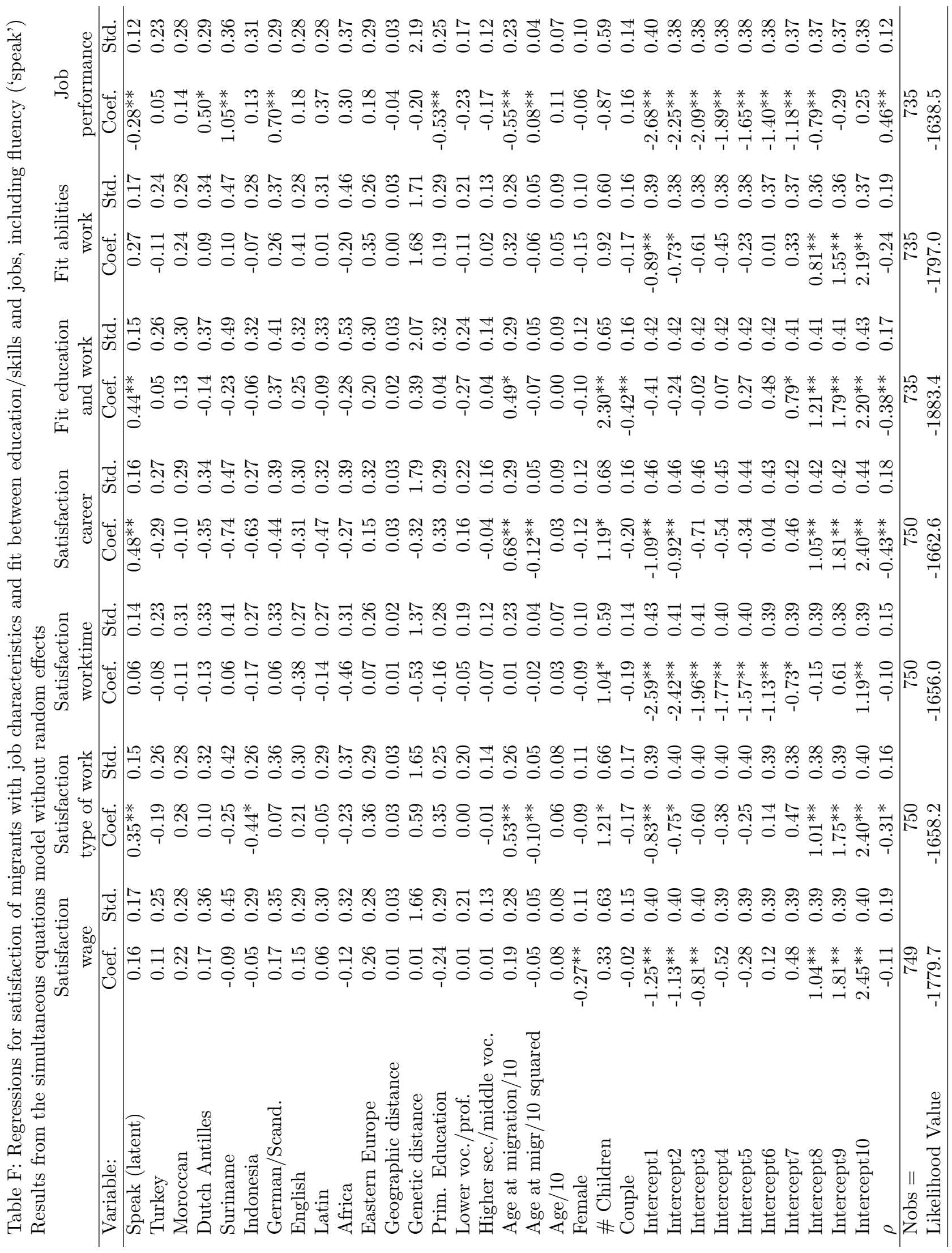




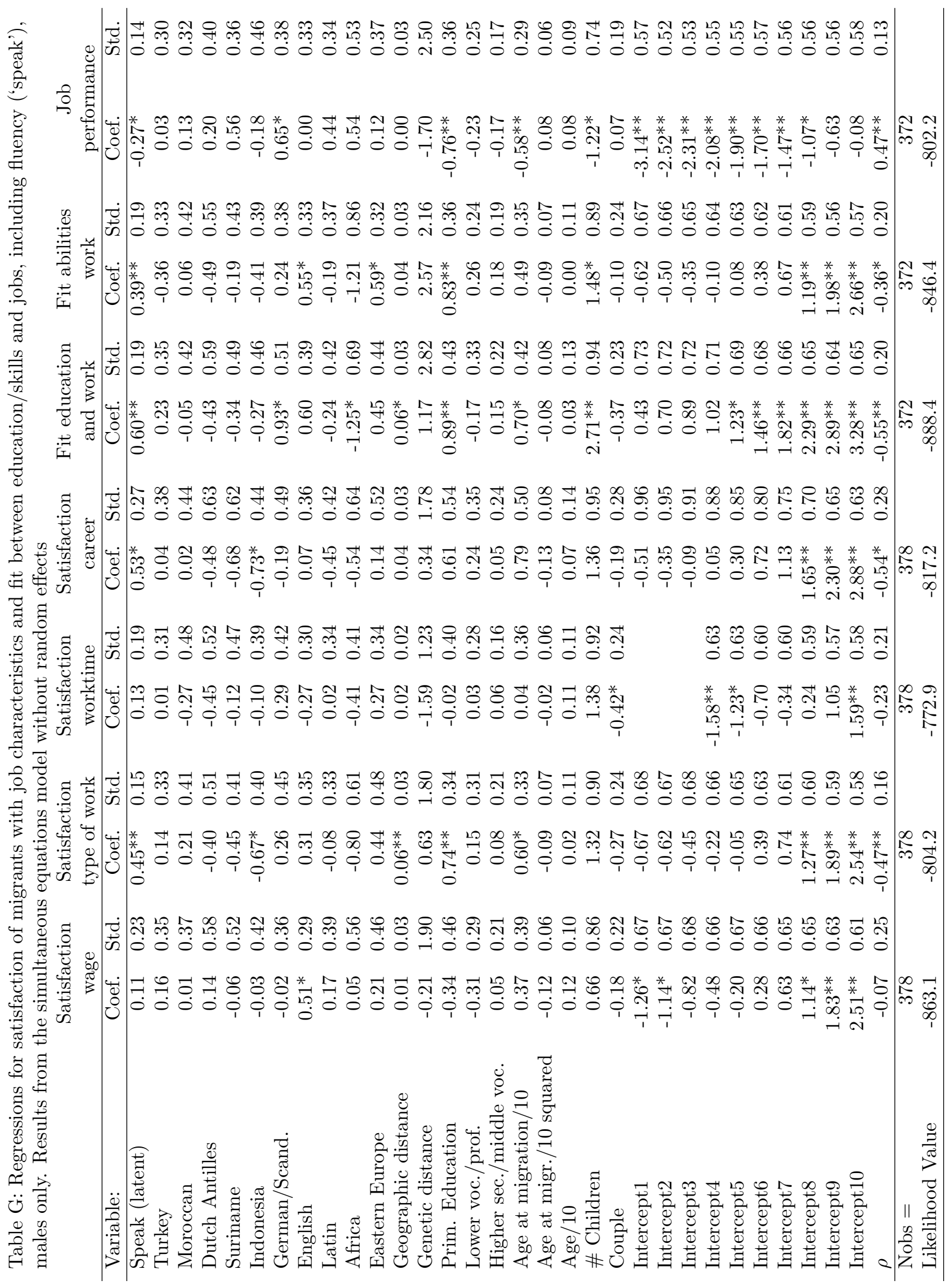




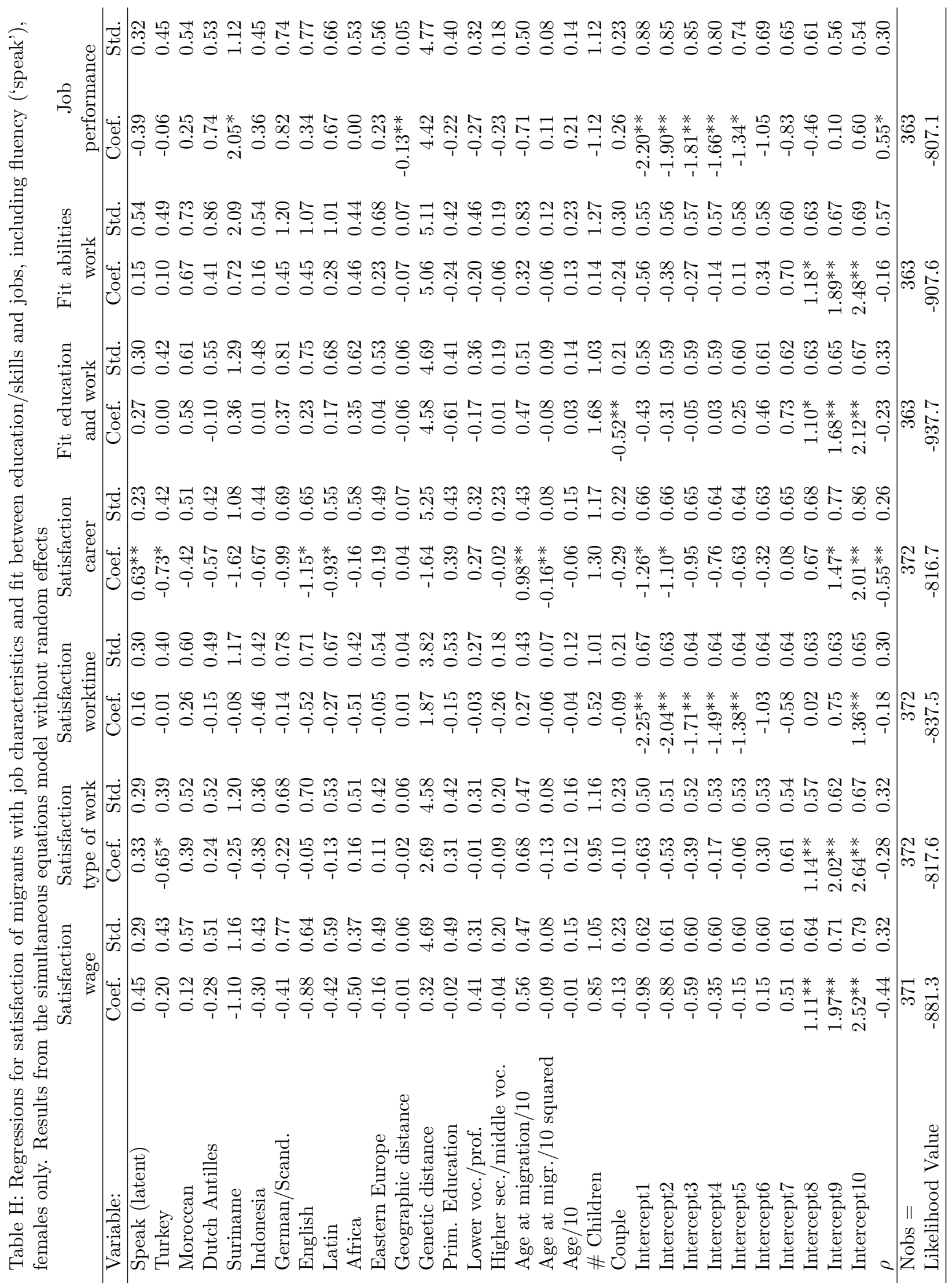




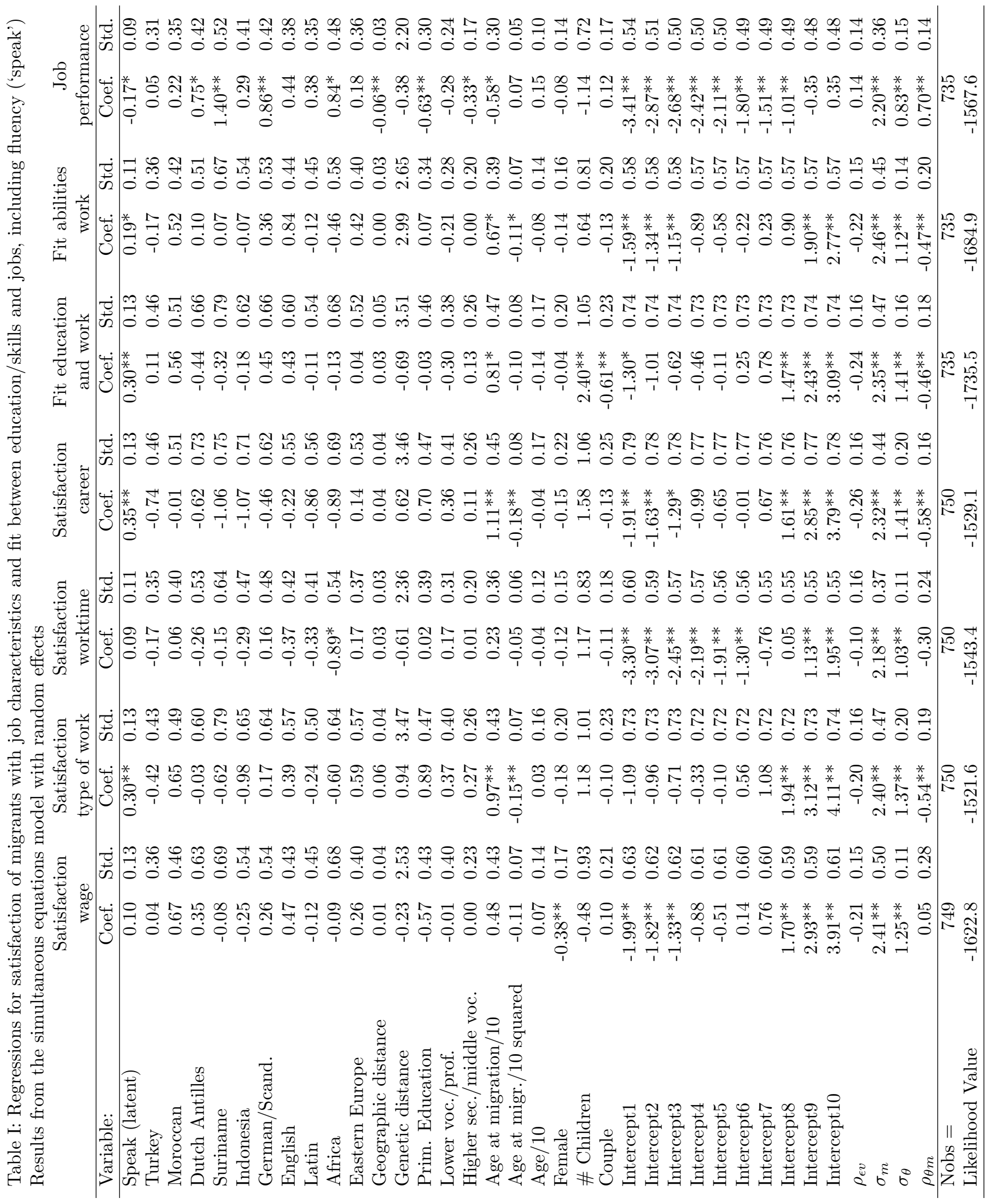




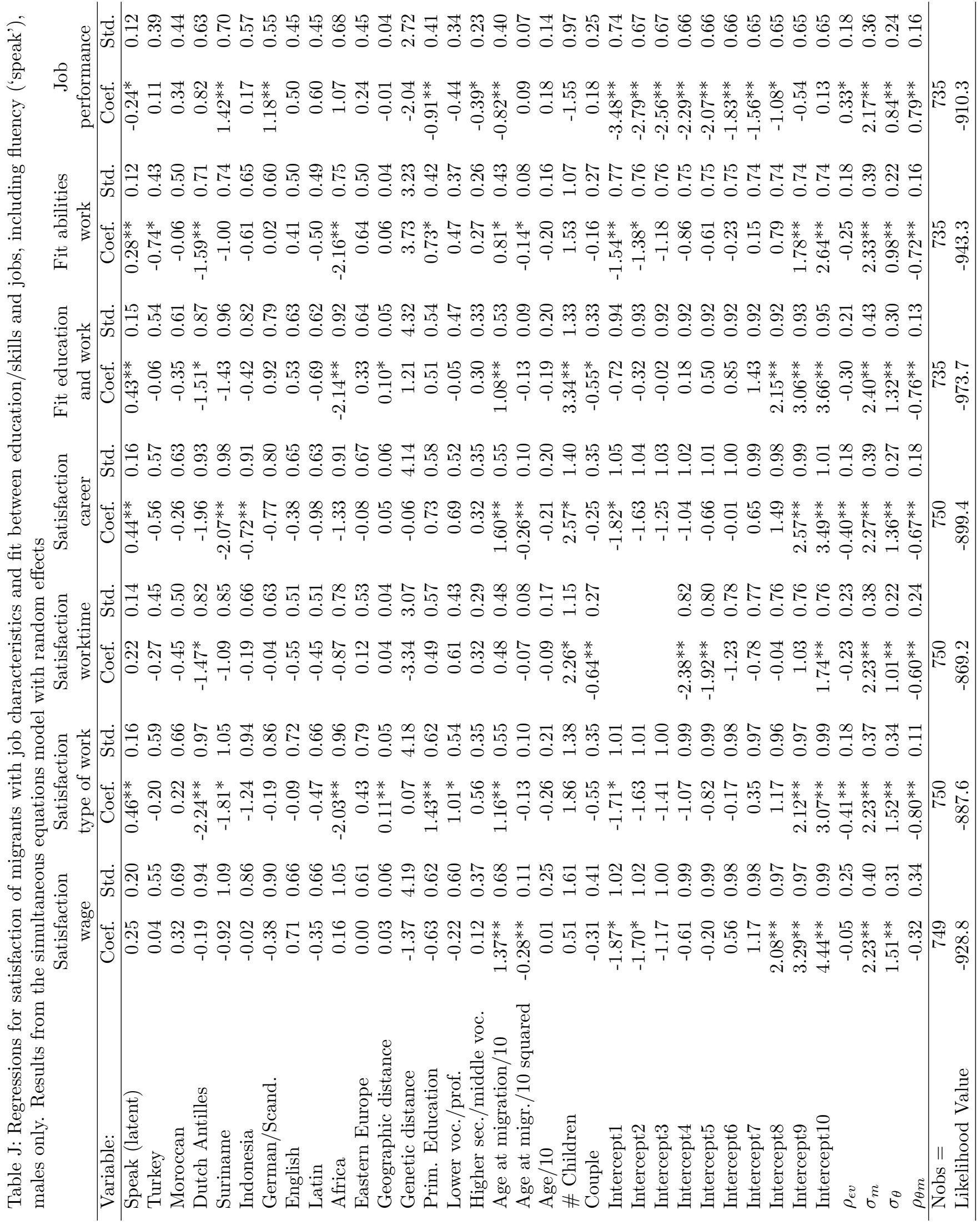




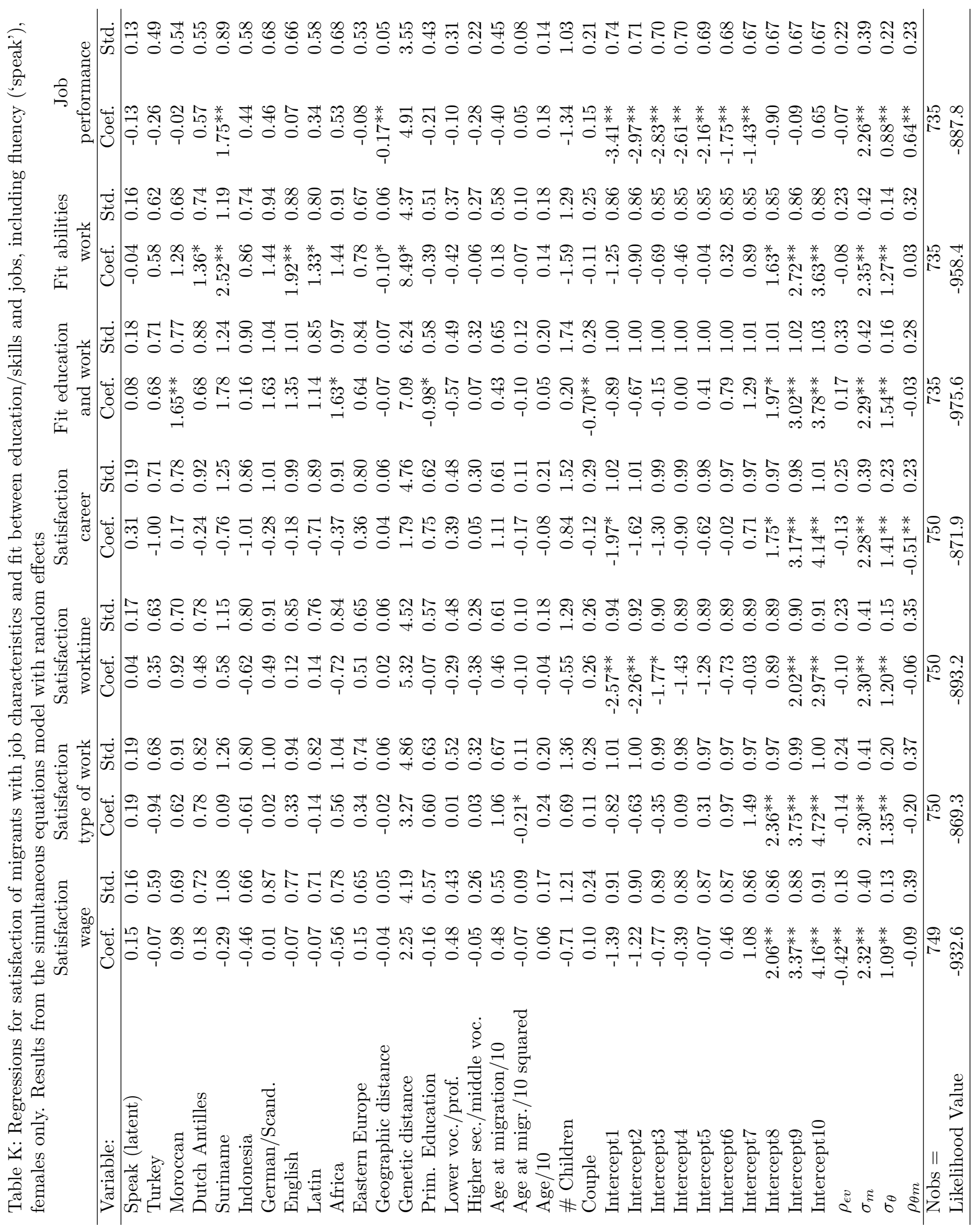


Table L: Sample statistics professional level

\begin{tabular}{|c|c|c|c|c|c|c|}
\hline & \multicolumn{2}{|c|}{ Both genders } & \multicolumn{2}{|c|}{ Male } & \multicolumn{2}{|c|}{ Female } \\
\hline & Native & Migrant & Native & Migrant & Native & Migrant \\
\hline Number of observations (NT): & 13,538 & 920 & 6,383 & 418 & 7,155 & 502 \\
\hline \multicolumn{7}{|l|}{ Professional level: } \\
\hline Higher academic or independent profession & 6.8 & 8.0 & 9.4 & 9.3 & 4.5 & 7.0 \\
\hline Higher supervisory profession & 8.3 & 5.8 & 12.8 & 9.1 & 4.2 & 3.0 \\
\hline Intermediate academic or independent profession & 25.4 & 21.4 & 17.0 & 14.4 & 32.9 & 27.3 \\
\hline Intermediate supervisory or commercial profession & 14.0 & 8.8 & 18.4 & 9.8 & 10.1 & 8.0 \\
\hline Other mental work & 24.9 & 24.4 & 15.1 & 15.6 & 33.7 & 31.7 \\
\hline skilled and supervisory manual work & 7.0 & 6.5 & 13.1 & 13.4 & 1.6 & 0.8 \\
\hline Semi-skilled manual work & 6.8 & 9.8 & 9.8 & 17.0 & 4.1 & 3.8 \\
\hline Unskilled and trained manual work & 5.2 & 12.8 & 2.2 & 7.7 & 7.8 & 17.1 \\
\hline Agrarian profession & 1.7 & 2.5 & 2.3 & 3.8 & 1.2 & 1.4 \\
\hline Total bottom 3 categories: & 13.7 & 25.1 & 14.3 & 28.5 & 13.1 & 22.3 \\
\hline \multicolumn{7}{|l|}{ Further explanation levels: } \\
\hline Professional level & \multicolumn{6}{|l|}{ e.g. } \\
\hline Higher academic or independent profession & \multicolumn{6}{|c|}{ architect, physician, scholar, academic instructor, engineer } \\
\hline Higher supervisory profession & \multirow{2}{*}{\multicolumn{6}{|c|}{$\begin{array}{l}\text { manager, director, owner of large company, supervisory civil servant } \\
\text { teacher, artist, nurse, social worker, policy assistant }\end{array}$}} \\
\hline Intermediate academic or independent profession & & & & & & \\
\hline Intermediate supervisory or commercial profession & \multicolumn{6}{|c|}{ head representative, department manager, shopkeeper } \\
\hline Other mental work & \multirow{2}{*}{\multicolumn{6}{|c|}{$\begin{array}{l}\text { administrative assistant, accountant, sales assistant, family carer } \\
\text { car mechanic, foreman, electrician }\end{array}$}} \\
\hline skilled and supervisory manual work & & & & & & \\
\hline Semi-skilled manual work & \multicolumn{6}{|c|}{ driver, factory worker } \\
\hline Unskilled and trained manual work & \multicolumn{6}{|c|}{ cleaner, packer } \\
\hline Agrarian profession & \multicolumn{6}{|c|}{ farm worker, independent agriculturalist } \\
\hline
\end{tabular}




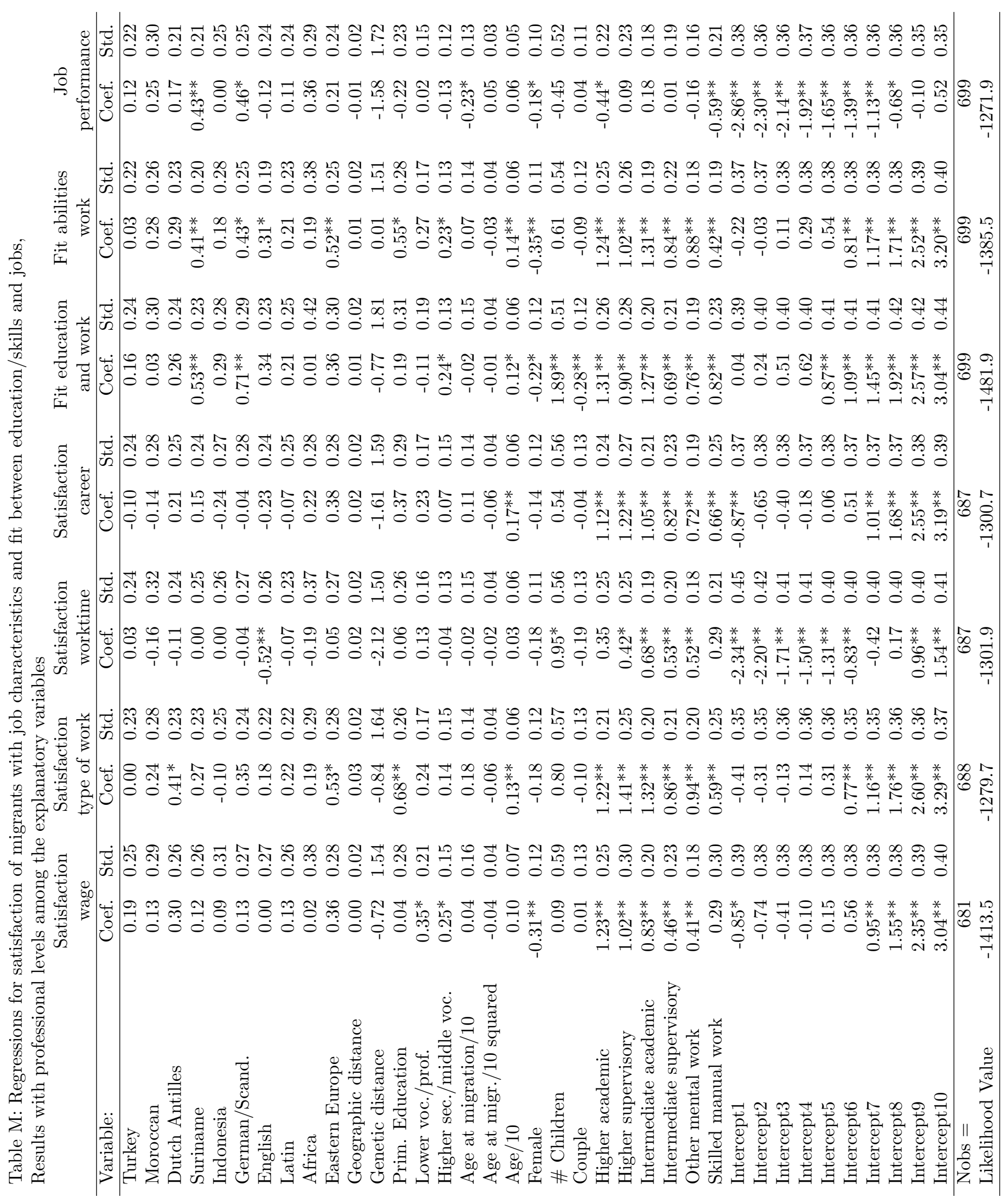




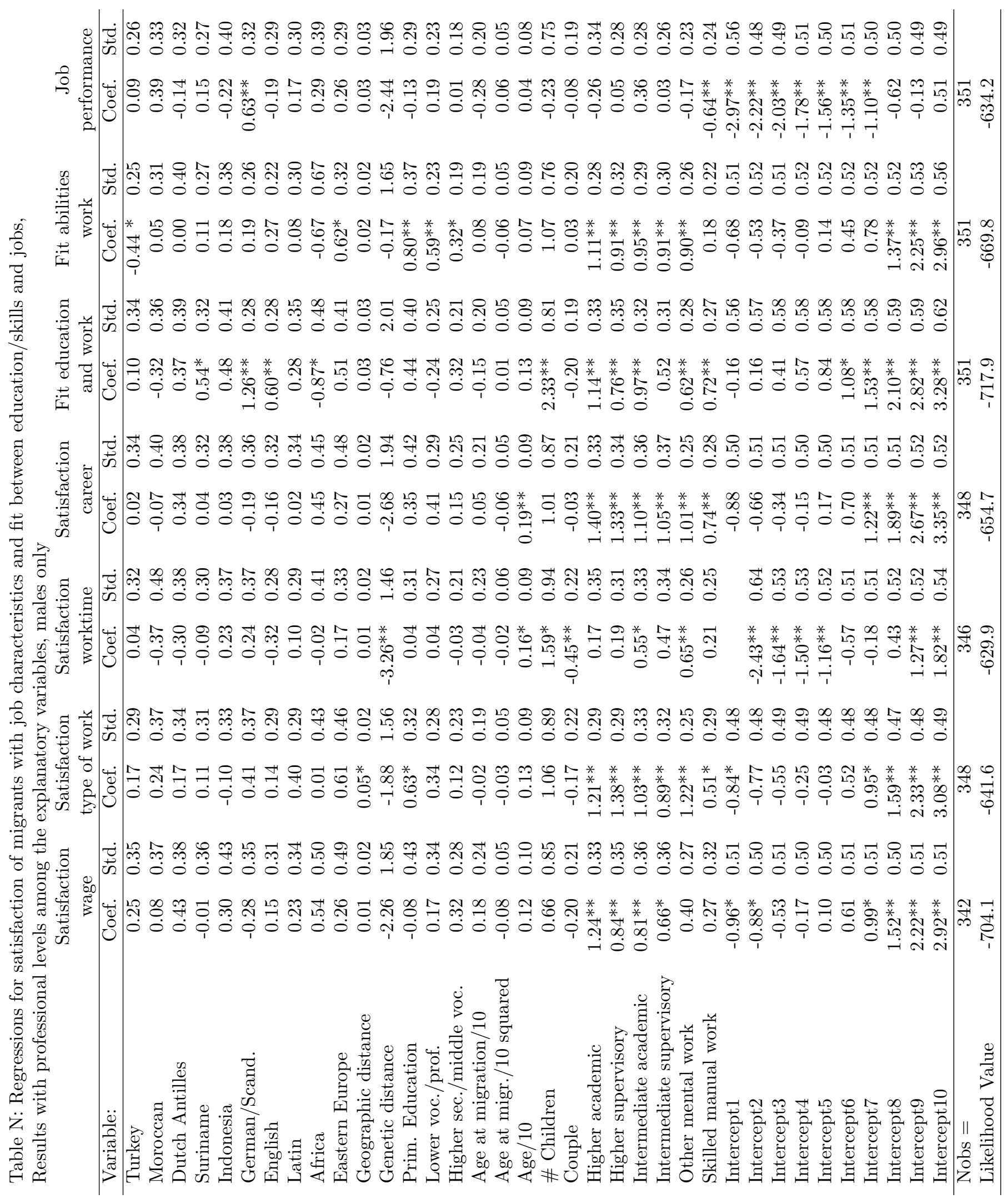




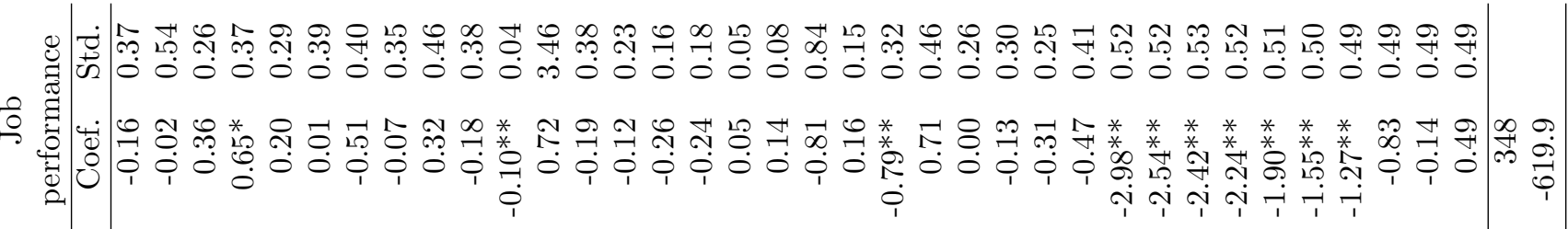

ש 㱒

를

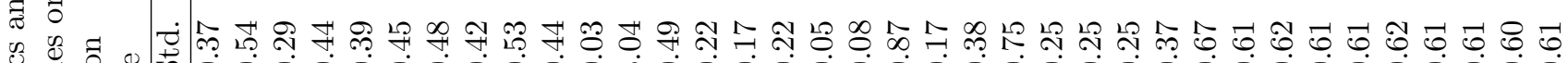

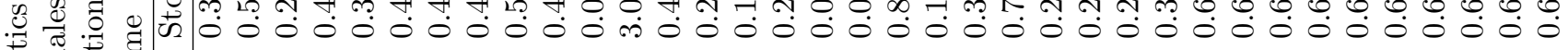
要

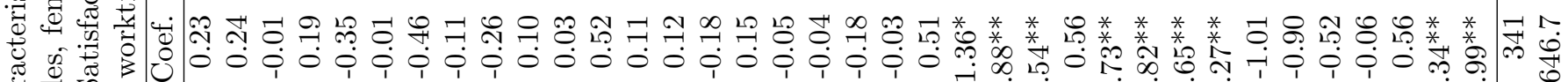

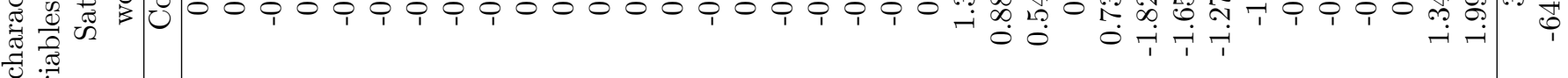

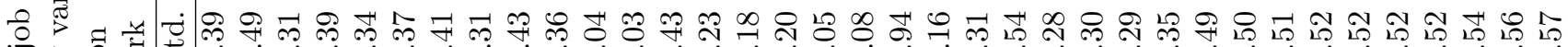

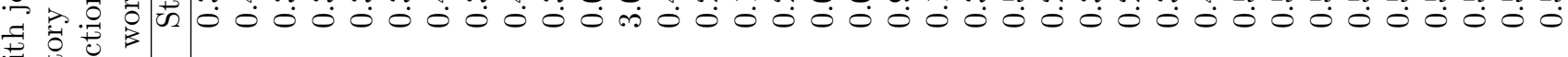

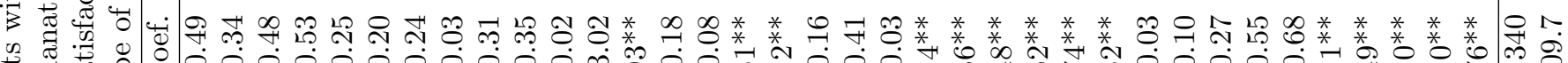

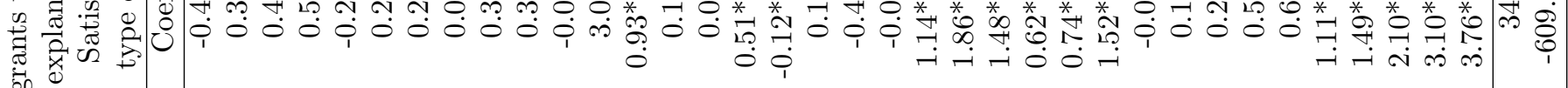
$\ddot{\Xi} \stackrel{g}{ \pm}$

山苻 0 . = I

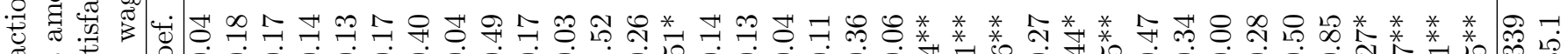

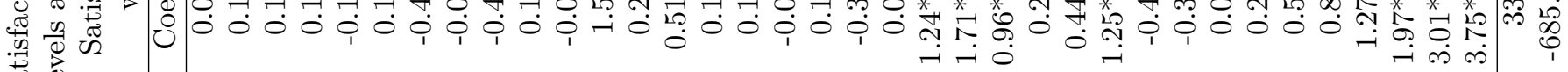
蛋

$\dot{0} \widetilde{0}$

2.

空

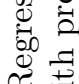

垔

○)

음

표

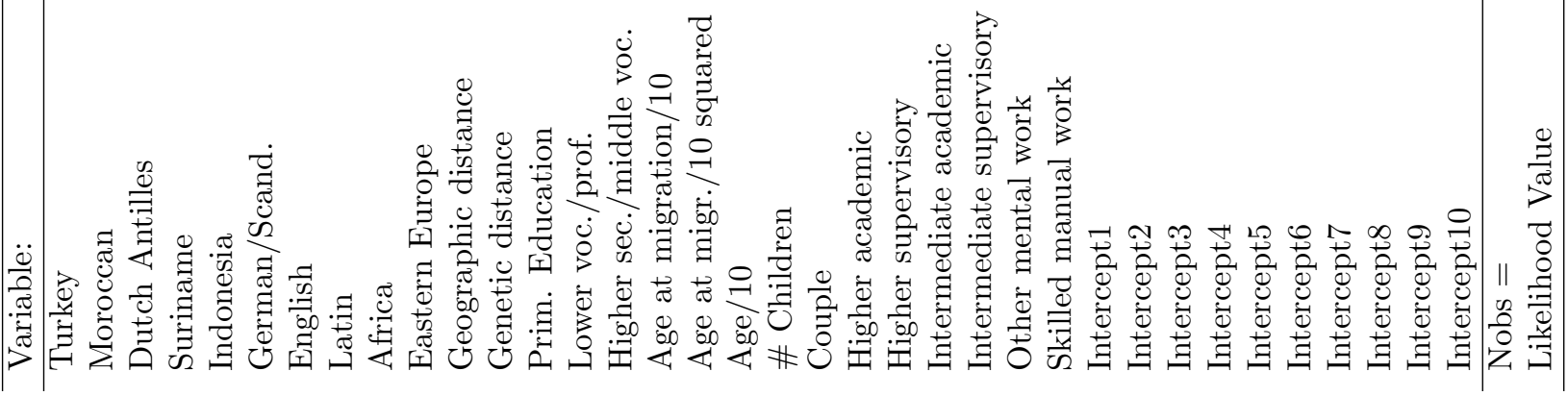

